\title{
¿Hay pereza fiscal territorial en Colombia?
}

Recibido: marzo, 28 de 2018 - Aprobado: julio, 16 de 2018

DoI: http://dx.doi.org/10.12804/revistas.urosario.edu.co/economia/a.7196

\author{
Jaime Bonet-Morón* \\ Gerson Javier Pérez-Valbuena* \\ Diana Ricciulli-Marín ${ }^{\dagger}$
}

\section{Resumen}

La mayor descentralización introducida en la Constitución Política de 1991 incrementó las transferencias a las entidades territoriales colombianas para que estas financiaran los nuevos gastos que debían asumir. Usando un modelo de dobles diferencias y un panel con efectos fijos, este documento evalúa si este aumento en las transferencias ha sido una fuente de pereza fiscal en los municipios colombianos. La investigación discrimina por tipo de municipios y por los dos fondos de transferencias vigentes (SGP y SGR). Los resultados muestran que, en el agregado, no hay evidencia de que las transferencias hayan afectado de manera negativa el recaudo municipal.

Palabras clave: pereza fiscal, sistemas de transferencias, política fiscal, Colombia. Clasificación JEL: H71, H77, C33.

* Banco de la República.

+ Banco de la República.

Diana Carolina Ricciulli-Marín. Dirección: Centro calle 33 \# 3-123. Cartagena Dтс (Colombia). Teléfono: (575) 6600808 ext. 5335. Correo electrónico: driccima@banrep. gov.co

Cómo citar este artículo: Bonet-Morón, J., Pérez-Valbuena, G. J., \& Ricciulli-Marín, D. (2018). ¿Hay pereza fiscal territorial en Colombia? Revista de Economía del Rosario, 21(2), 247-307. Dor: http://dx.doi.org/10.12804/revistas.urosario.edu.co/economia/a.7196 


\title{
Is there subnational fiscal laziness in Colombia?
}

\begin{abstract}
The greater decentralization introduced by the Political Constitution of 1991, increased intergovernmental transfers for municipalities and departments to finance their own expenses. Through a model of double differences and fixed effects panel data, this document evaluates whether this increase in transfers has been a source of fiscal laziness in Colombian municipalities. The analysis distinguishes between types of territorial entities and between the two current schemes of funds transferring (SGP and SGR). All in all, the results show that there is no evidence that the increasing intergovernmental transfers have affected municipal tax collections negatively.
\end{abstract}

Keywords: Fiscal laziness, transfer's systems, fiscal policy, Colombia. JEL Classification: H71, H77, C33.

\section{¿Há preguiça fiscal territorial na Colômbia? \\ Resumo}

A maior descentralização introduzida na Constituição Política de 1991, incrementou as transferências às entidades territoriais colombianas para que elas financiaram os novos gastos que deviam assumir. Usando um modelo de duplas diferenças e um painel com efeitos fixos, este documento avalia se este aumento nas transferências tem sido uma fonte de preguiça fiscal nos municípios colombianos. A pesquisa discrimina por tipo de municípios e pelos dois Fundos de transferências vigentes (SGP e SGR). Os resultados mostram que, no agregado, não há evidência de que as transferências tenham afetado de maneira negativa a arrecadação municipal.

Palavras-chave: preguiça fiscal, sistemas de transferências, política fiscal, Colômbia. Classificação JEL: H71, H77, C33. 


\section{Introducción}

Colombia es el país unitario con mayor descentralización del gasto en América Latina. De acuerdo con el BID (2012), el gasto promedio de los gobiernos subnacionales (GSN) como proporción del PIB en América Latina alcanzaba el 9,8\% a finales de la década de 2000. Tres países federales de la región se ubicaban en los primeros lugares, Brasil (21,5\%), Argentina (15,6\%) y México $(10,6 \%)$. Dentro de los unitarios, Colombia encabezaba con un gasto subnacional cercano al 10,4\% del рів. Porto et al. (2017) indican que, aproximadamente, el $39 \%$ del gasto público colombiano es ejecutado por los GSN: departamentos $(18 \%)$ y municipios $(21 \%)$.

La descentralización colombiana fue profundizada por la Constitución Política de 1991. Para asegurar el éxito de este proceso, la Carta Política estableció que las competencias que se descentralizaban debían estar acompañadas por los correspondientes recursos para asumirlas. Se procedió, en ese momento, a transferir responsabilidades principalmente en tres sectores: educación, salud y saneamiento básico. A su vez, para financiar las nuevas competencias se establecieron dos fondos: el situado fiscal y las participaciones municipales. A lo largo de los últimos 20 años, estos fondos han tenido varias reformas en la búsqueda de una mayor equidad y eficiencia, que terminaron con la creación del Sistema General de Participaciones (SGP).

Además de estos recursos, la Constitución estableció que las regalías provenientes de la explotación de recursos minero-energéticos eran propiedad de las entidades territoriales donde se realizaba la explotación y transporte del producto. En la medida en que eran pocos los departamentos y municipios con recursos minero-energéticos en su suelo, la distribución de las regalías estaba altamente concentrada en pocos territorios: siete departamentos concentraban el 70\% de los recursos asignados en el período 2002-2011 (Bonet y Urrego, 2014). Esta situación llevó a una reforma del esquema de distribución que constituyó el Sistema General de Regalías (SGR).

El SGP y el SGR se constituyen en las más importantes transferencias a los GSN. En 2015 estos representaban el 3,8\% y el 1,5\% del PIB, respectivamente. Si bien existen también recursos que invierte el gobierno nacional directamente a través de la inversión programada en el presupuesto general de la nación (PGN), el SGP y el SGR son las transferencias ejecutadas directamente por los GSN. El SGP son recursos condicionados a determinados sectores, mientras que los del SGR no están etiquetados y los GSN tienen libertad para decidir en qué proyectos se invierten. Sin embargo, los dos son asignados a los departamentos y municipios de acuerdo con los criterios definidos en un marco regulatorio. 
Es un hecho que la descentralización colombiana ha sido menor por el lado de los ingresos que por el de los gastos. Según información del Ministerio de Hacienda y Crédito Público (Мнср) y las ejecuciones presupuestales del Departamento Nacional de Planeación (DNP), aproximadamente el $80 \%$ de los ingresos corrientes (tributarios y no tributarios) fueron recaudados por el gobierno central en 2014. Por su parte, los ingresos recaudados por los GSN están agrupados en pocos municipios. En efecto, Bogotá, Medellín, Cali, Barranquilla y Cartagena recaudaron el 55 \% del total de los ingresos corrientes municipales. En la medida en que la actividad económica está concentrada en pocos territorios, la capacidad local de generación de ingresos es más fuerte en aquellos con mayores bases tributarias.

Lo anterior implica que los GSN enfrentan una alta dependencia de las transferencias afectando su autonomía fiscal. Esta situación ha dado pie al desarrollo de varias investigaciones que buscaron determinar el impacto de la mayor descentralización sobre la estabilidad macroeconómica nacional y el efecto de las mayores transferencias en la generación de recursos propios o desempeño fiscal en los GSN. Muchos de los primeros trabajos se concentraron en analizar las implicaciones macroeconómicas de la descentralización a finales de la década de los noventa, cuando se presentaron problemas en la sostenibilidad de las finanzas públicas territoriales que llegaron a comprometer la estabilidad fiscal nacional (Junguito et al., 1995; Fainboim et al., 1997; Alesina, 2002; Lozano, 2001). Según Alesina (2002), la separación de recaudo y gasto entre distintos niveles del gobierno condujo a muchos departamentos y municipios a la acumulación de deuda y al crecimiento de su déficit operacional. En particular, Melo (2001) encuentra que el aumento de las transferencias resultó en un mayor gasto en las entidades territoriales (flypaper effect), especialmente en las que más dependían de esta fuente de ingresos.

Existen otros estudios que buscaban evaluar si el mayor proceso de descentralización pudo causar pereza fiscal, es decir, si ante los mayores recursos transferidos, los gobiernos subnacionales recaudaban menos ingresos propios. Sánchez et al. (1994) concluían que, a pesar de que no existe evidencia empírica para confirmar pereza fiscal ante la presencia de transferencias, esta podría llegar a generarse. Estos autores consideraban que los municipios pueden fortalecer sus ingresos mediante reformas administrativas más que tributarias, ya que los impuestos locales son una fuente dinámica potencial de recaudos, pero los problemas administrativos y los atrasos de los avalúos catastrales impiden que lleguen a su óptimo. En relación con esto, Zapata et al. (2001) concluyen que la descentralización produjo muy poca autonomía financiera local. Los autores afirman que esto se debió a bases tributarias locales poco dinámicas, un crecimiento elevado del gasto territorial que no 
logró ser financiado con las crecientes transferencias y que condujo a situaciones de endeudamiento que amenazaron la sostenibilidad de varias entidades territoriales.

Posteriormente, Cadena (2002) no encontró evidencia de pereza fiscal en los municipios, dado que los ingresos tributarios municipales mejoraron simultáneamente con el aumento de las transferencias. Esta autora concluye que el esfuerzo fiscal es diferencial de acuerdo con las características demográficas y socioeconómicas de cada municipio. En línea con este resultado, Zapata (2010) y Zapata (2016) tampoco encuentran evidencia de pereza fiscal, por el contrario, los resultados que obtienen revelan un mayor dinamismo en los ingresos corrientes que en las transferencias.

Existen algunos trabajos recientes que también abordan el desempeño fiscal en los GSN colombianos, pero se concentraron en el efecto de las regalías. Uno de los primeros trabajos en esta línea fue el de Perry y Olivera (2009), quienes no encuentran efectos importantes de pereza fiscal en los territorios receptores de regalías, contrario a lo que ocurre con las transferencias de ingresos corrientes nacionales. En los últimos años, las investigaciones de Ramírez y Bedoya (2014) y Martínez (2017) concluyen que sí hay evidencia de pereza fiscal, en particular un menor esfuerzo para la recaudación del impuesto predial en aquellos municipios con una alta participación de las regalías en los ingresos totales. Sin embargo, estos trabajos analizan un período previo a la creación del SGR. Por último, en un análisis de este sistema sobre el desempeño fiscal municipal en el primer año de aplicación, Bonet et al. (2014) encontraron que donde la participación de las regalías en sus ingresos totales es menor o igual al $20 \%$, el desempeño fiscal se deteriora a medida que se incrementa la dependencia de regalías. Por el contrario, si dicha participación es superior al $20 \%$, el desempeño fiscal mejora, pero la magnitud de la inversión se deteriora.

El principal objetivo de este trabajo es revisar la hipótesis de pereza fiscal en los municipios de Colombia. Para ello, se usan dos aproximaciones distintas: un modelo de dobles diferencias y un panel con efectos fijos. A diferencia de los estudios anteriores, este documento abarca un período más amplio de tiempo, de modo que se pueden observar los efectos de los cambios experimentados por los sistemas de transferencias. Adicionalmente, se discrimina por tipo de municipio y por los dos fondos de transferencias vigentes, con el fin de determinar patrones propios de acuerdo con el tamaño de la municipalidad y el sistema de transferencia. Los resultados muestran que, en el agregado, no hay evidencia de que el SGP y el SGR hayan afectado negativamente el recaudo municipal. Sin embargo, este comportamiento es diferencial entre los diferentes tamaños de municipio y en el tiempo. Además, 
el efecto positivo resulta ser menor con las regalías que con las transferencias del situado fiscal, participaciones municipales y SGP.

Es importante aclarar que la no presencia de pereza fiscal territorial no implica que los municipios y departamentos estén explotando su potencial recaudatorio plenamente. Aquí probablemente se requiere revisar el esfuerzo fiscal de los GSN, en lo que, como lo plantean Pessino y Fenochieto (2010), es necesario tener claro qué se entiende por este concepto. Estos autores proponen dos aproximaciones al esfuerzo fiscal: i) estimándolo como la relación entre la recaudación efectiva y la capacidad tributaria y ii) calculándolo como la relación entre la recaudación efectiva y la potencial. La primera se aborda generalmente usando la carga tributaria, mientras que la segunda requiere la estimación de la base tributaria dentro del esquema legal vigente para la estimación de los tributos. Para el caso colombiano, Bonet y Ayala (2016) estimaron que los municipios recaudan en promedio el 34,6\% del potencial estimado y los departamentos cerca del 79,4\%. Para lograr explotar el potencial tributario, las entidades territoriales colombianas deberán realizar un mayor esfuerzo fiscal del que han venido haciendo.

El documento está compuesto de cinco secciones. La segunda sección describe los principales cambios en el marco regulatorio del SGP y del SGR. La tercera sección muestra la evolución de los recursos transferidos por los dos sistemas a los GSN en los últimos 20 años, así como el comportamiento que han tenido los recursos propios de los departamentos y municipios en ese período. La cuarta sección analiza la relación existente entre los recursos transferidos y la generación de recursos propios en las entidades territoriales. Por último, la quinta sección presenta las principales conclusiones que surgen del estudio.

\section{Principales cambios en las transferencias a GSN}

Como se mencionó anteriormente, las transferencias más importantes del gobierno nacional a los GSN en Colombia son el SGP y el SGR. Estas transferencias fueron definidas en la Constitución Política de 1991 y desde ese momento han sufrido importantes modificaciones. Con el fin de poner estos hechos en contexto, esta sección describe los principales cambios en el marco regulatorio de las transferencias mencionadas. 


\subsection{Sistema General de Participaciones $(S G P)^{1}$}

Con la puesta en marcha de la descentralización fiscal adoptada a partir de la Constitución de 1991, se dio inicio a dos mecanismos a través de los cuales las entidades territoriales recibirían recursos por parte del gobierno central, el situado fiscal en el caso de los departamentos (incluyendo al Distrito Capital y los distritos de Barranquilla, Cartagena y Santa Marta) y las participaciones municipales. La Carta Política colombiana estableció que las transferencias subnacionales deberían estar ligadas como un porcentaje de los ingresos corrientes de la nación (ICN). El situado fiscal para los años 1994, 1995 y 1996 correspondería al $23 \%, 23,5 \%$ y $24,5 \%$ de los ICN, respectivamente, tomando como referencia que para 1993 estos representaban el 22,1\%. A partir de 1997 esta participación en los ICN se mantendría constante en un $24,5 \%$. Por su parte, las participaciones municipales equivalían al $14 \%$ de los ICN en 1993 y se incrementarían un punto adicional cada año hasta alcanzar el $22 \%$ en 2001 (figura 1).

Desde un principio se estableció que se debía distribuir el 15\% del situado fiscal entre los departamentos y distritos especiales de Bogotá, Cartagena, Barranquilla y Santa Marta en partes iguales. El 85\% restante dependía de la población atendida en el año anterior y la población por atender en salud y educación. Adicionalmente, se consideraban el esfuerzo fiscal ponderado y la eficiencia administrativa de cada entidad territorial.

Como mínimo, cada entidad territorial debía destinar el $60 \%$ de los recursos del situado fiscal al financiamiento de la educación, y un $20 \%$ a salud. El $20 \%$ restante podía ser destinado a salud o educación, dependiendo de las metas de coberturas en estos dos sectores. Los departamentos se encargarían de distribuir los recursos entre sus municipios según los mismos criterios: la población por atender y el histórico de la población atendida. En el caso de las participaciones, el $30 \%$ debía destinarse a educación, el $25 \%$ a salud, el $20 \%$ a agua potable y saneamiento básico, el $5 \%$ a recreación y cultura, y el restante $20 \%$ a libre inversión.

Con la caída del producto interno bruto (РIB) de finales de los noventa se redujo el monto de los ICN y, en consecuencia, las transferencias a los GSN, poniendo en riesgo los recursos que garantizaban las coberturas en salud y educación. En esos momentos, Colombia enfrentaba una severa crisis fiscal en la que la situación financiera territorial comprometió la estabilidad macroeconómica. Conforme con el MHCP (2015), luego de la profundización del proceso de descentralización contemplado en la Constitución Política de 1991,

1 Esta sección está basada en Bonet y Pérez (2016). 


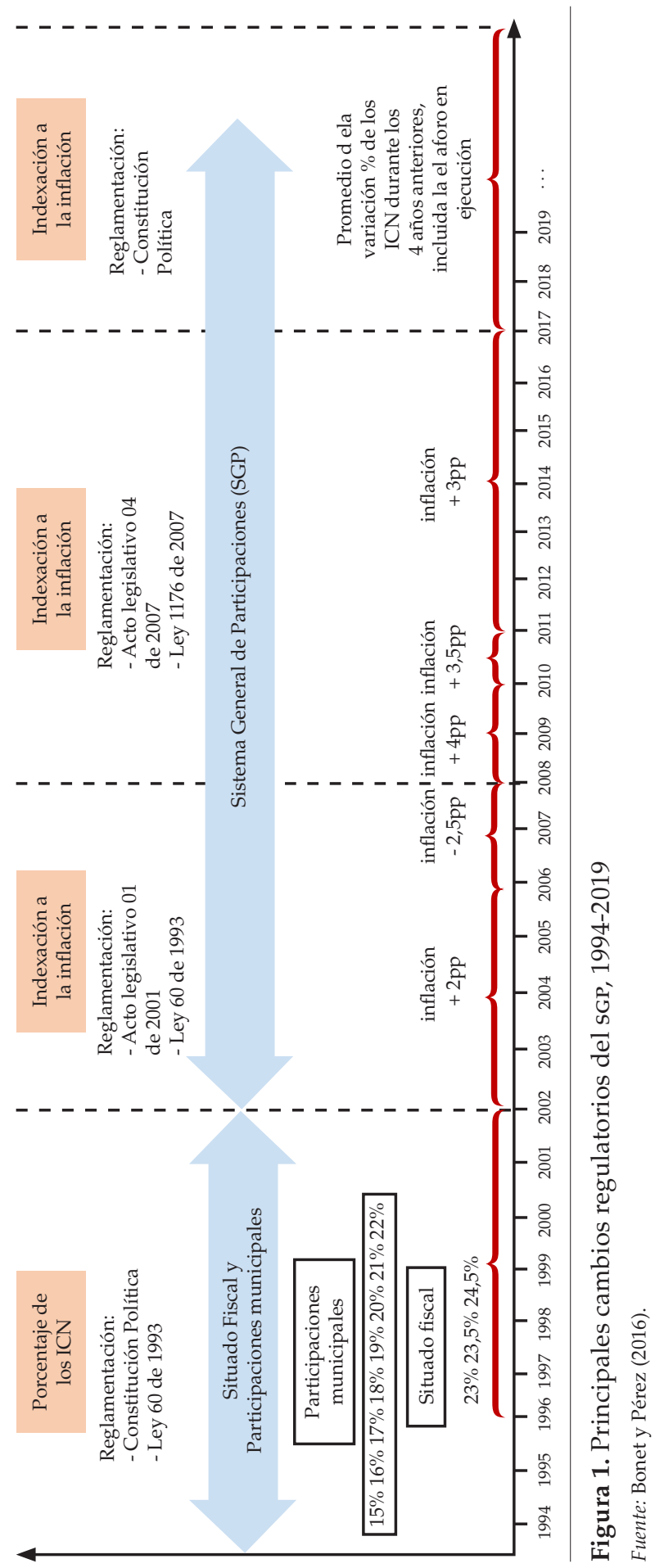


se observó un incremento significativo en el gasto público subnacional, el cual pasó del 2,8 \% del Рів en 1990 al 9,4% del PIв en 1999. Este ascenso se originó, en gran parte, por los mayores gastos de funcionamiento y personal en los sectores de educación y salud. Lo anterior generó una tendencia creciente en el déficit de los gobiernos territoriales, al pasar del 0,18\% del PIB en 1990 al 0,43\% del рів en 1999.

Esta coyuntura llevó al gobierno nacional a pensar en una estrategia alternativa. El objetivo principal era desligar el valor de las transferencias de porcentajes fijos de los ICN, con el fin de asegurar crecimientos reales en los montos recibidos por los municipios y departamentos, que garantizarían el sostenimiento de los sectores salud, educación y saneamiento básico. La estrategia utilizada para buscar este objetivo fue la de indexar los crecimientos de los montos de las transferencias a la inflación. Es así como, a través del Acto Legislativo 1 de 2001, se reformaron los artículos 356 y 357 de la Constitución Política, y se creó el sGP, que sería reglamentado por la Ley 715 del mismo año. De esta manera, el SGP agruparía en una sola bolsa lo que antes hacía parte del situado fiscal y las participaciones municipales (Bonet et al., 2014).

El artículo 357 de la Constitución Política habría establecido que, en el largo plazo, el monto del sGP crecería anualmente en un porcentaje igual al promedio de la variación de los ICN de los últimos cuatro años, incluido el valor del aforo en ejecución. Sin embargo, estableció que transitoriamente lo haría ligado a la inflación de la siguiente forma: la inflación causada más un crecimiento real constante equivalente al 2,0\% entre 2002 y 2005, y del 2,5\% entre 2006 y 2008 (Acto Legislativo 1 de 2001). Igualmente, quedó también establecido que, en los años en que la economía creciera por encima del $4 \%$, el SGP tendría un crecimiento adicional en los puntos porcentuales que superara a dicha tasa de crecimiento. Sin embargo, cuando el crecimiento estuviera por debajo de la meta establecida, el gobierno nacional central (GNC) debería cubrir el faltante para mantener la tasa de crecimiento. En los casos de un crecimiento anual por encima del $4 \%$, el GNC podría descontar los recursos que aportó para mantener la meta de crecimiento del SGP.

Esta transitoriedad, que inicialmente llegaba hasta 2008, se extendió por medio del Acto Legislativo 4 de 2007 y la Ley 1176 del mismo año. Nuevamente, a través de un parágrafo transitorio, se establecieron los crecimientos reales a partir de 2008 así: para 2008 y 2009 el sGP crecería en la inflación causada más 4 puntos porcentuales (pp), en 2010 inflación causada más 3,5 pp y entre 2011 y 2016 inflación causada más 3 pp (figura 1). De este modo, según lo establecido en la Constitución Nacional, en 2016 finalizó la transitoriedad y en 2017 empezó a operar la nueva fórmula de cálculo de crecimiento porcentual del SGP, en donde los incrementos estarán ligados nuevamente a los ICN, pero esta 
vez no como un porcentaje fijo de estos, sino con incrementos que consideran el promedio de la variación porcentual de los ICN en los últimos cuatro años.

También cambió la destinación de los recursos, pues a partir del año 2002 el sGP no solo contemplaría las participaciones para salud y educación, sino que se agregó en el rubro de propósito general, que corresponde a agua potable y saneamiento básico, recreación, cultura y deporte, libre destinación, recursos para los resguardos indígenas y los municipios ribereños al río Magdalena, financiamiento de programas de alimentación escolar en los distritos y municipios, y recursos para el Fondo Nacional de Pensiones de las Entidades Territoriales (Fonpet).

Para la distribución de los recursos, la Ley 715 de 2001 inicialmente descontaba el $4 \%$ de los recursos del SGP para ser distribuido entre los resguardos indígenas $(0,52 \%)$, municipios ribereños al río Magdalena $(0,08 \%)$, municipios y distritos para programas de alimentación escolar $(0,5 \%)$ y para el Fonpet $(2,9 \%)$. Una vez descontados estos recursos, la participación para el sector educativo se estableció en el 58,5\%, para el sector de la salud fue del $24,5 \%$ y para propósito general el restante $17 \%$. En efecto, a diferencia de lo establecido por la Ley 60 de 1993, en la cual se fijó un porcentaje de recursos que luego se repartía entre los departamentos y distritos para después ser distribuido en los diferentes sectores, con la Ley 715, primero se estableció un porcentaje de recursos para cada uno de los sectores, que posteriormente se repartiría entre los municipios, distritos y departamentos.

En 2007 se hizo una nueva reforma constitucional mediante el Acto Legislativo 4 (MHCP, 2006) y se aprobó la Ley 1176 de 2007, la cual modificó algunos artículos de la Ley 715 de 2001. Así, a partir de 2007 se separaron los servicios de agua potable y saneamiento básico de la participación de propósito general, asignándole sus propios recursos. De esta manera, una vez descontados los recursos del SGP para los resguardos indígenas, municipios ribereños al río Magdalena, programas de alimentación escolar y para el Fonpet, el 58,5\% de los recursos se destinaría a educación, el $24,5 \%$ a salud, el 11,6 \% a propósito general y el $5,4 \%$ a agua potable y saneamiento básico.

Para el caso particular del sector salud, la Ley 1438 de 2011 determinó que el $10 \%$ de los recursos destinados para salud deberían financiar actividades de salud pública. Adicionalmente, con esta ley se crea el Fondo de Salvamento y Garantías para el Sector Salud (Fonsaet), el cual tenía como propósito asegurar el pago de las obligaciones de las empresas sociales del Estado intervenidas, o en riesgo de estarlo por parte de la Superintendencia de Salud. Este fondo está financiado por un monto que no supera el $10 \%$ de los recursos de la salud que del sGP se transfieren para oferta, además de los excedentes destinados para la salud recaudados directamente por la nación. 


\subsection{Sistema General de Regalías (SGR)}

Uno de los cambios más importantes en los recursos de los GSN fue el incremento de las regalías, debido al boom minero-energético entre 2002 y 2012. La expansión en la producción tuvo un impacto significativo en las regalías, las cuales pasaron de representar el 0,6\% del PIB en 2002 al 1,6\% en 2012. Dado lo establecido en la Constitución Política de 1991, las regalías se convirtieron en una fuente importante de financiación de proyectos de los GSN. Para los municipios, estos fondos representan el doble de lo recaudado por los tributos municipales más importantes, el impuesto predial y el impuesto de industria y comercio (ICA). Por su parte, las regalías llegaron a ser diez veces el recaudo departamental del impuesto a los licores.

En la medida en que la Constitución estableció que las regalías eran propiedad de las entidades territoriales donde se realizaba la explotación y transporte del producto, su distribución estaba altamente concentrada en pocos territorios. Esto llevó a una reforma del esquema de distribución que constituyó el SGR, con la intención de lograr una redistribución más equitativa de los recursos y una mayor calidad en el gasto ejecutado. En la mayoría de las entidades territoriales, los recursos aumentaron: 28 de los 32 departamentos incrementaron sus regalías totales (Bonet y Urrego, 2014). En algunos territorios productores, como el departamento Casanare, la reducción en las regalías directas fue compensada por un aumento en los recursos a otros fondos, distribuidos con criterios de pobreza relativa y población. Por otro lado, el monto total de regalías pasó de casi $\$ 6$ billones en 2011 a \$10,4 billones en 2012, contribuyendo igualmente a un incremento en estos recursos a lo largo de todo el territorio.

En cuanto a la mayor calidad del gasto, una característica general del SGR es que los fondos no pueden ser ejecutados hasta que los GSN encargados formulen un proyecto que mejore las condiciones de vida, y que además esté coordinado con los planes de desarrollo territoriales. Estos proyectos son evaluados de acuerdo con criterios como viabilidad, priorización y coordinación con objetivos macroeconómicos generales. Los encargados de esta evaluación son los órganos colegiados de administración y decisión (OCAD) (figura 2).

Si bien los OCAD son una característica general del sistema, su composición varía según los distintos rubros en los que ahora se compone el SGR, el cual está conformado por nueve fondos: i) Fondo de Ahorro y Estabilización (FAE), ii) Fondo Nacional de Pensiones de las Entidades Territoriales (Fonpet),

2 Esta sección está basada en Bonet y Urrego (2014). 

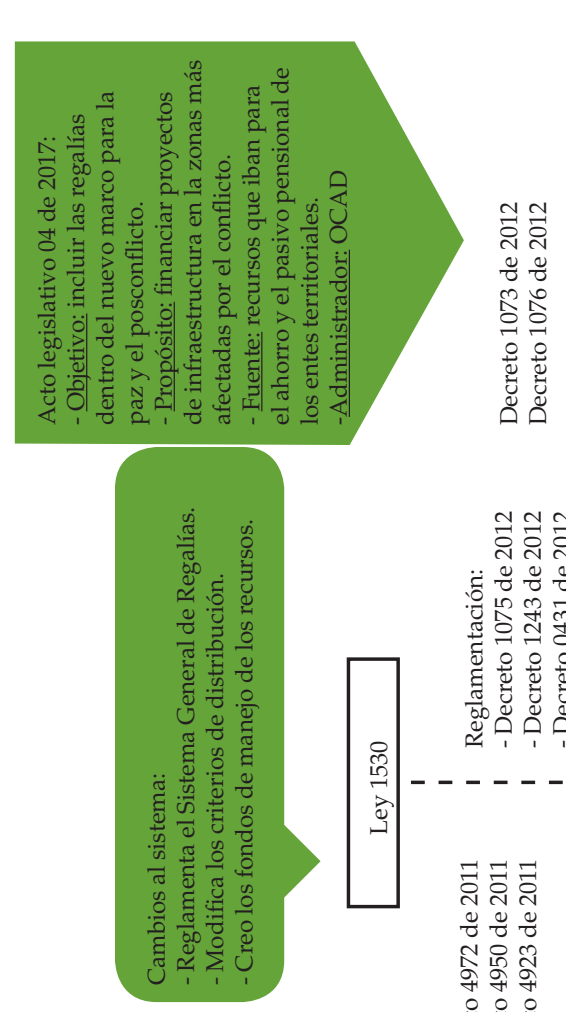

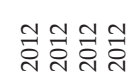

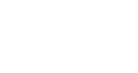

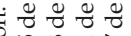

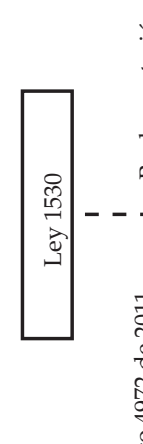

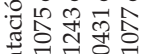

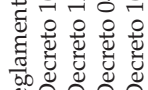

品

ีㅗํํํำ

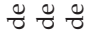

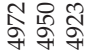

오오

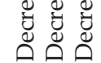

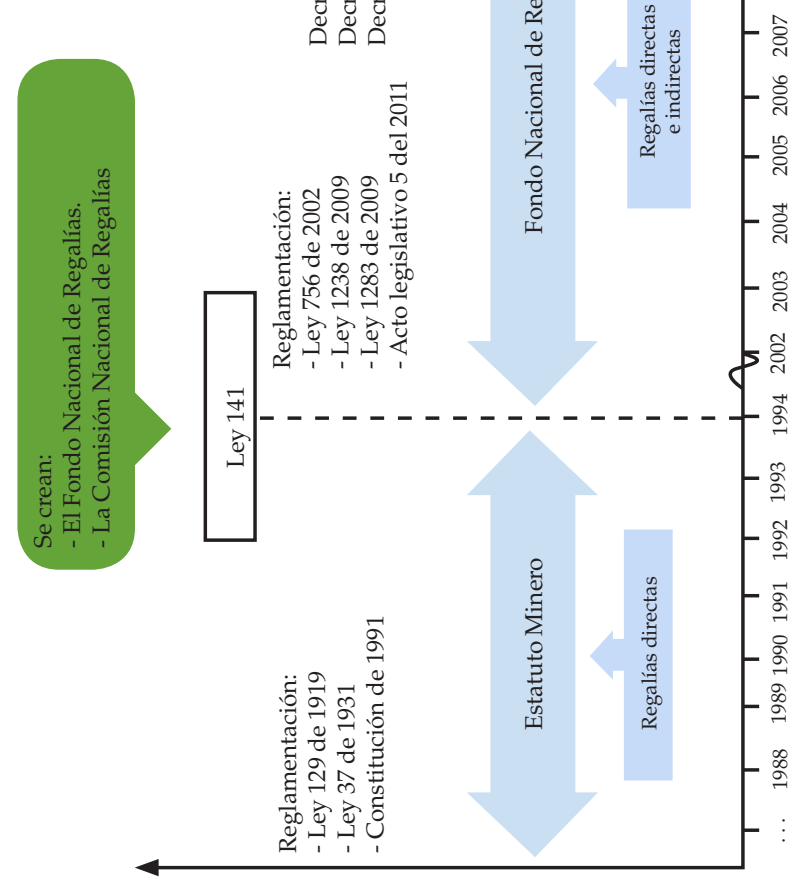

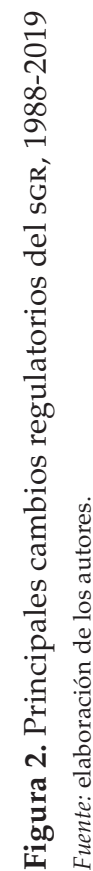


iii) Fondo de Ciencia, Tecnología e Innovación (FстеI), iv) Fondo de Desarrollo Regional (FDR), v) Fondo de Compensación Regional (FCR), vi) regalías directas, vii) fiscalización de la exploración y explotación de los yacimientos, y el conocimiento y cartografía geológica del suelo, viii) funcionamiento del sistema de monitoreo, seguimiento, control y evaluación del SGR, y ix) funcionamiento del sGR.

Los tres últimos rubros descritos no tienen una asignación territorial específica y son ejecutados por entidades del gobierno nacional. Para la fiscalización de la exploración y explotación, se destina el $2 \%$ de todos los recursos; para el monitoreo, seguimiento, control y evaluación del sGR, el 0,7\%; y para el funcionamiento del sGR, el 1,3\%. Adicional a estos recursos existe un rubro que no se encuentra en la lista anterior y es un 0,5\% destinado a proyectos de inversión en los municipios ribereños al río Magdalena, los cuales son ejecutados por los GSN que se ubican en la zona y en algunos casos específicos por la Corporación Autónoma Regional del Río Grande de la Magdalena (Cormagdalena). Los fondos antes descritos ascienden al 4,5\% de los ingresos percibidos por regalías, luego el SGR que se distribuye entre los GSN corresponde al 95,5\% de las regalías. La tabla 1 incluye la distribución del SGR en los distintos fondos, discriminando lo establecido por ley contra las asignaciones presupuestales realizadas.

Tabla 1. Distribución del Sistema General de Regalías

\begin{tabular}{|c|c|c|c|c|c|}
\hline \multirow[b]{2}{*}{ Fondo } & \multirow[b]{2}{*}{ Legal (2015 en adelante) } & \multicolumn{4}{|c|}{ Asignaciones } \\
\hline & & 2012 & 2013-2014 & $2015-2016$ & 2017-2018 \\
\hline FAE & hasta un $30 \%$ & $20 \%$ & $19 \%$ & $23 \%$ & $7 \%$ \\
\hline Fonpet & $10 \%$ & $10 \%$ & $10 \%$ & $10 \%$ & $10 \%$ \\
\hline FCTeL & $10 \%$ & $10 \%$ & $10 \%$ & $10 \%$ & $10 \%$ \\
\hline FDR & $16 \%$ & $8 \%$ & $16 \%$ & $18 \%$ & $23 \%$ \\
\hline FCR & $24 \%$ & $16 \%$ & $24 \%$ & $27 \%$ & $35 \%$ \\
\hline Regalías directas & $10 \%$ & $35 \%$ & $21 \%$ & $11 \%$ & $15 \%$ \\
\hline \multicolumn{2}{|c|}{ Monto Total Presupuesto (Billones de pesos) } & 7,9 & 16,8 & 16,6 & 11,1 \\
\hline
\end{tabular}

El fAE fue pensado como un posible mecanismo para reducir la variabilidad de los recursos provenientes por regalías a través de los años y se distribuyen de acuerdo con la participación que tiene cada uno de los departamentos en la distribución de los otros fondos. El Fonpet se distribuye teniendo en cuenta el pasivo pensional de los departamentos y municipios, mientras que el FCTeI 
va a los departamentos teniendo en cuenta la distribución de los recursos del FCR y el FDR. Para tal fin, la ocAD de ciencia, tecnología e innovación, única en el país, se encarga de la aprobación de los proyectos susceptibles de ser financiados. La participación de los fondos regionales (FDR y FCR) será residual, ya que del total del sGR debe descontarse lo correspondiente a los fondos antes mencionados. El porcentaje de recursos restantes son divididos entre las regalías directas y los fondos regionales, los cuales a partir de 2015 representan un $10 \%$ y un $40 \%$ del sGR, respectivamente.

Luego de asignados los recursos correspondientes a los fondos regionales, estos son divididos nuevamente en dos fondos: FCR y FDR. Al primero le corresponde el $60 \%$ y al segundo, el $40 \%$. El FDR se distribuye únicamente entre departamentos y se hace según dos criterios fundamentales: el $60 \%$ de los recursos de acuerdo con la proporción de la población del departamento en el total nacional y el $40 \%$ restante según criterio de pobreza relativa medida como proporción del NBI departamental en el total nacional. Por su parte, el FCR se fragmenta en tres rubros adicionales. El primero corresponde al $60 \%$ de todo el fondo y se reparte entre los departamentos con NBI mayor al $30 \%$ o que tengan municipios con un NBI mayor al $35 \%$. La distribución se hace de acuerdo con la población, la proporción del NBI en el total nacional y el desempleo departamental. El segundo rubro corresponde al $30 \%$ del fondo y se entrega a los municipios más pobres (NBI >35\%), con el fin de financiar proyectos de impacto local. El 10\% restante del FCR sirve para financiar igualmente proyectos de impacto local, pero en municipios de cuarta, quinta o sexta categoría que tengan un NBI menor o igual al $35 \%$ y que no reciban recursos del $30 \%$ correspondiente al segundo rubro. ${ }^{3}$

El más reciente proyecto de reforma, aprobado el 8 de septiembre mediante el Acto Legislativo 4 de 2017, tiene como propósito incluir las regalías dentro del nuevo marco para la paz y el posconflicto. Mediante esta reforma, y en un plazo de 20 años, se abrirá un fondo con el $7 \%$ de las regalías para financiar proyectos de infraestructura en las zonas más afectadas por el conflicto. Para crearlo se tomarán recursos que iban para el ahorro y el pasivo pensional de los entes territoriales, y su administración estará a cargo de una ocAD. Esta última se encargará de priorizar los proyectos teniendo en cuenta cuáles son las regiones donde el conflicto fue más devastador y garantizará la inversión en proyectos que impulsen una paz estable y duradera (MHCP, 2017).

3 Los municipios en Colombia se clasifican en categorías de 1 a 6 y categoría especial de acuerdo con su número de habitantes y a sus ingresos corrientes de libre destinación (ICLD). La categoría 6 agrupa a los municipios con menor volumen de ICLD y menos habitantes, mientras que en la categoría especial se encuentran aquellos con mayor ICLD y número de habitantes. 
Si bien las reformas al sistema han generado avances en términos de equidad, aún persisten problemas de eficiencia en el manejo de los recursos. En cuanto a la equidad, Hernández y Herrera. (2015) encuentran que la asignación de las regalías en el nuevo esquema parece estar explicada por las condiciones socioeconómicas y que, en general, los departamentos en peores condiciones tienen una mayor asignación de recursos. No obstante, el impacto de estos recursos sobre el crecimiento y desarrollo regional es limitado. Según el más reciente informe de la Contraloría General de la República (CGR, 2015), persisten dificultades en la aprobación de proyectos y el cumplimiento de sus requisitos, generando lentitud en la ejecución, así como un alto costo institucional. Además, una parte importante de los recursos se estarían destinando a proyectos de bajo impacto socioeconómico, que en muchos casos no aportan al mejoramiento de las necesidades sociales de la población.

\section{Evolución de las transferencias y la autonomía fiscal}

Con el fin de contextualizar el análisis, esta sección presenta la evolución de las finanzas públicas de los departamentos y municipios en Colombia. Se describen los principales hechos estilizados sobre recaudos de ingresos propios y transferencias, así como de la estructura de gastos, teniendo en cuenta el tamaño de las entidades territoriales.

\subsection{Principales cuentas de ingresos y gastos de las entidades territoriales}

La tabla 2 muestra las principales fuentes de ingresos y gastos de los gobiernos departamentales (panel a) y los municipales (panel b), los montos para tres momentos en el tiempo y su participación en cada uno de ellos dentro del ingreso y el gasto total. ${ }^{4}$ De los resultados se pueden observar algunas características importantes. La primera es que los municipios y departamentos tienen dos fuentes principales de ingreso y gasto, los corrientes y los de capital. Dentro de los ingresos, es posible notar que la participación de los ingresos corrientes y de capital era similar hace dos décadas.

4 Los tres momentos de tiempo, 1996, 2001 y 2015, corresponden: el primero al inicio de las dos últimas décadas, que, de igual forma, coincide con el momento en el que ya estaban en firme los cambios en las transferencias introducidos luego de la Constitución de 1991. El segundo es el momento previo al nuevo cambio en las transferencias, que, entre otras cosas, dio origen al Sistema General de Participaciones (SGP). El tercer momento hace referencia al último año disponible. 


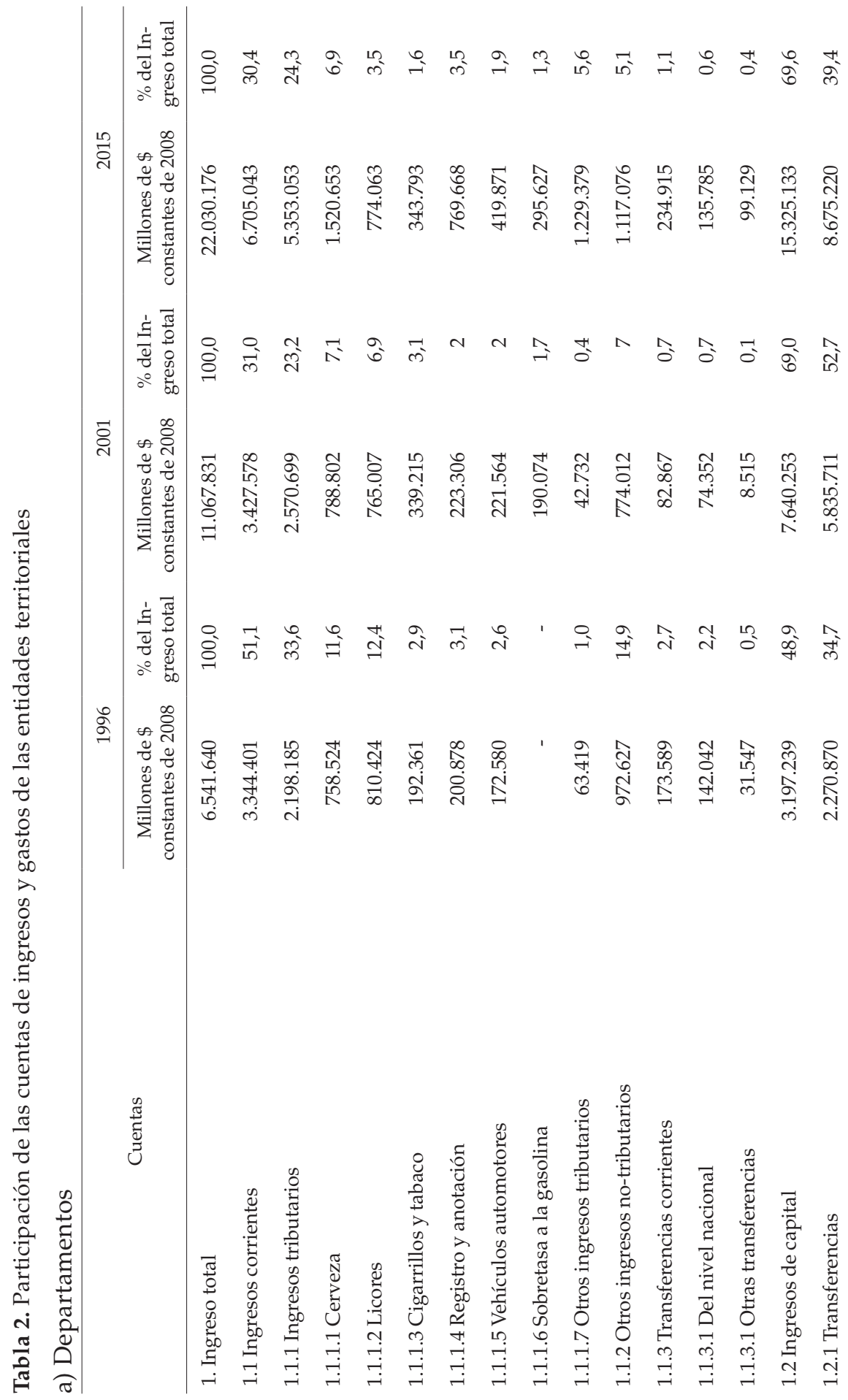




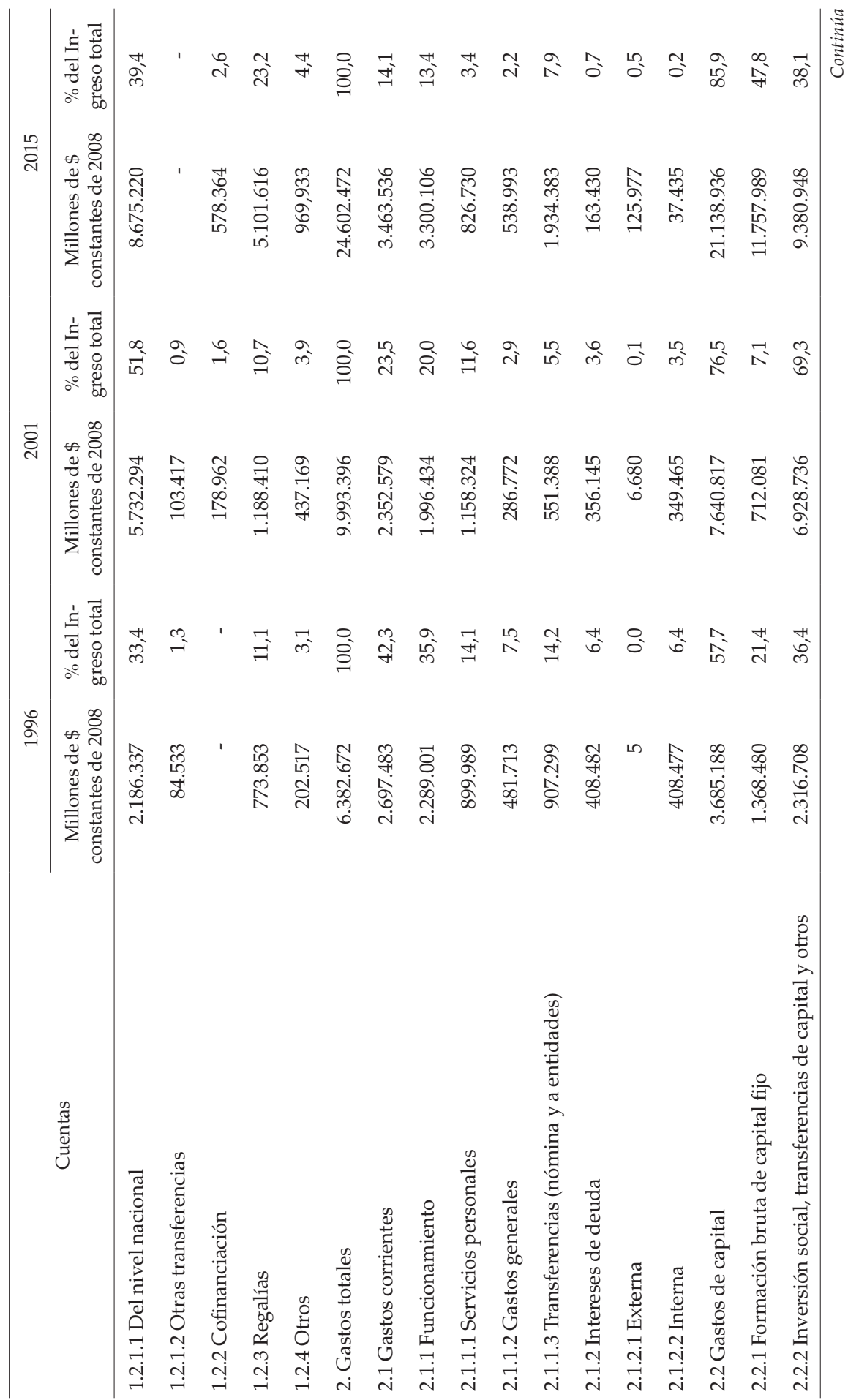




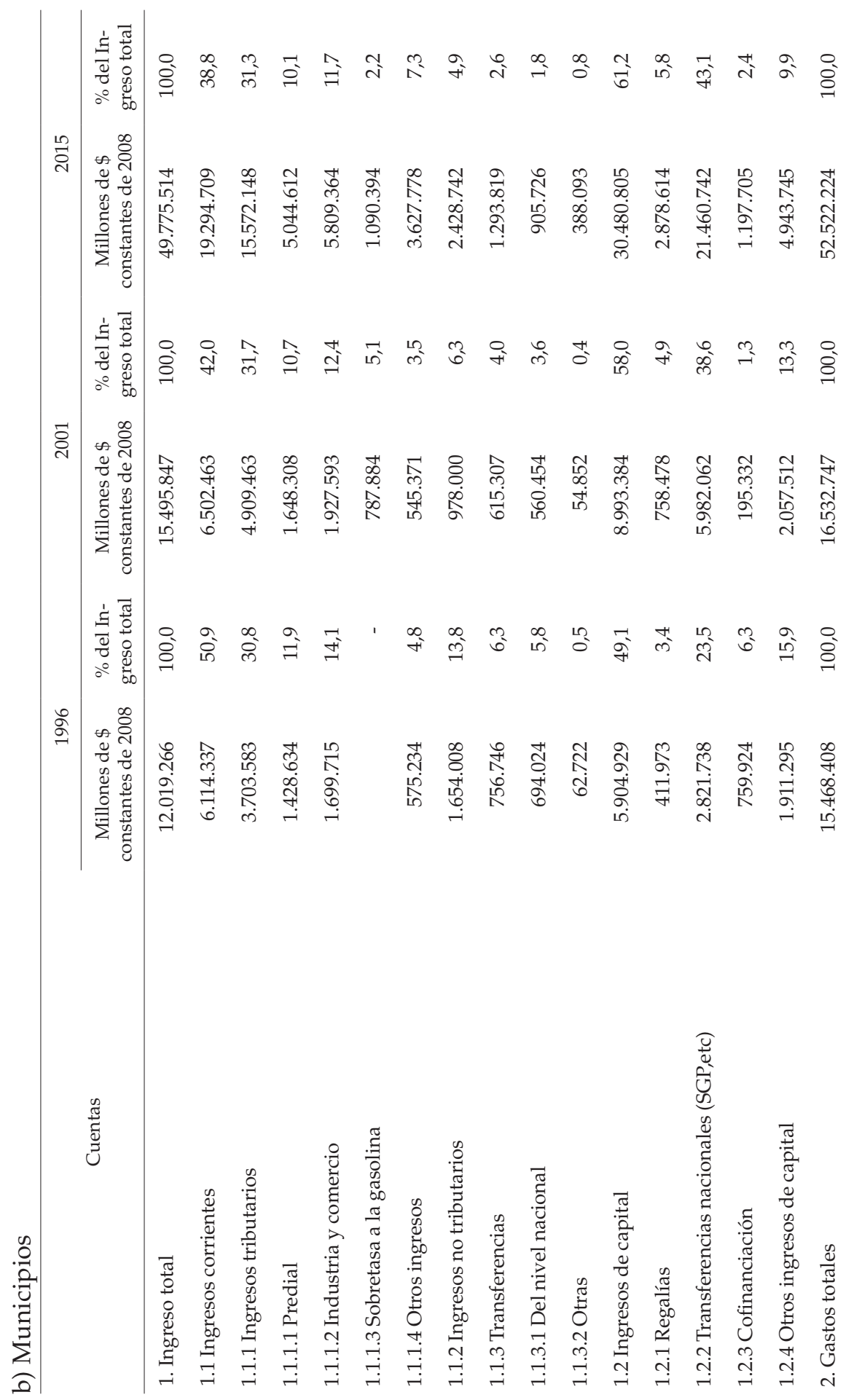




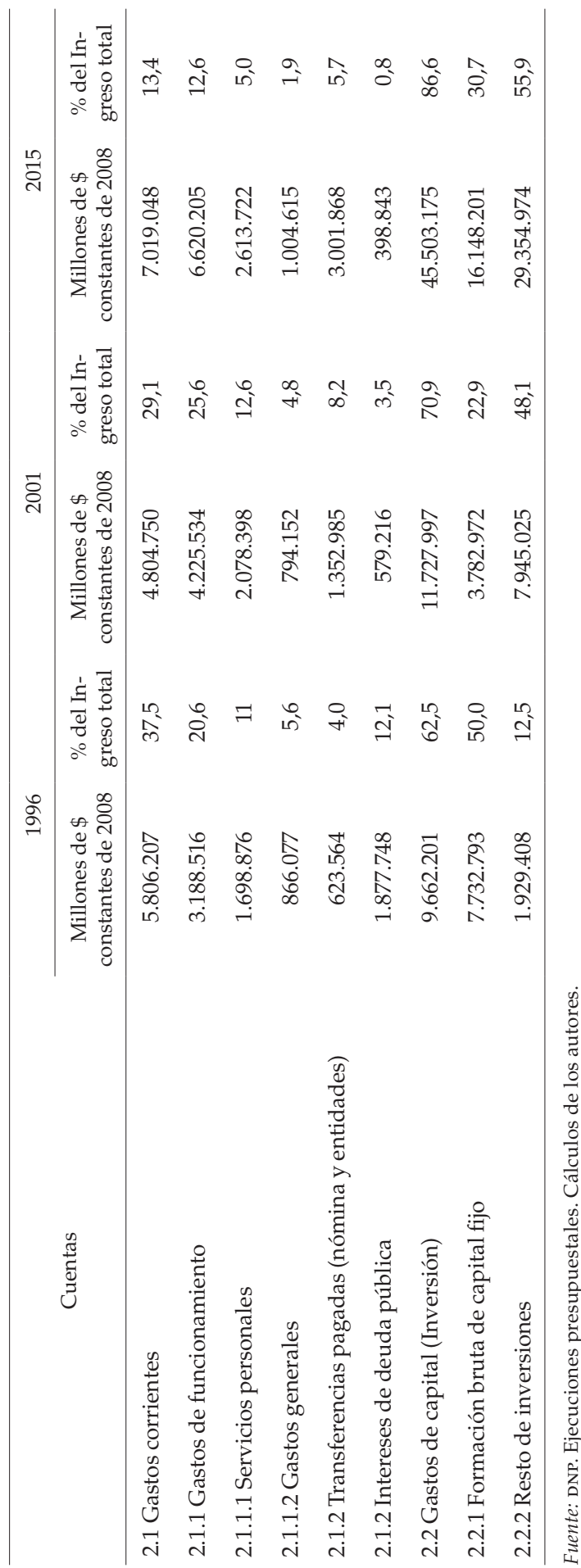


Dentro de los ingresos corrientes, los tributarios representaban en 1996 cerca de la tercera parte de los ingresos totales. Dentro de los ingresos de capital, las transferencias nacionales tenían también una participación cercana a la tercera parte del total de ingresos en el caso de los departamentos, mientras que para los municipios las transferencias nacionales tenían una menor participación, cerca de la cuarta parte de los ingresos totales. Del lado de los gastos, los de capital, conformados por la formación bruta de capital fijo y el resto de inversiones, han dominado el total de gastos. En 1996, estos representaban el 57,7\% para los departamentos y el 62,5\% para los municipios.

Una segunda característica tiene en cuenta la dinámica en la participación de las subcuentas de ingresos y gastos, las cuales, a su vez, dependen del período de análisis y de la entidad territorial que se considere. Por ejemplo, para los departamentos se observa, entre 1996 y 2001, una clara reducción en la importancia de los ingresos tributarios —en cerca de 10 puntos porcentuales (pp) - y un aumento en el caso de las transferencias nacionales —en cerca de 20 pp-, en otras palabras, aumentó la dependencia de las transferencias. En el mismo período en los municipios, aunque parecen haber mantenido la participación de los ingresos tributarios en cerca de la tercera parte de los ingresos totales, las transferencias pasaron de representar el 23,5\% en 1996 a representar el 38,6\% en 2001, lo que tiene el mismo efecto de aumento en la dependencia de las transferencias.

Para el período 2002-2015 la situación es un poco distinta, especialmente en el caso de los departamentos. Esto debido a que después de la creación del SGP, estas entidades territoriales lograron aumentar levemente la participación de los ingresos tributarios y reducir la dependencia de las transferencias. En el caso de los municipios, la participación de los ingresos tributarios se mantuvo en cerca de la tercera parte de los ingresos totales, mientras que las transferencias se incrementaron en cerca de $4 \mathrm{pp}$.

Una tercera característica tiene que ver con los gastos. Mientras los corrientes han venido decreciendo en participación, al pasar del 42,3\% al 14,1 \% en los departamentos y del 37,5\% al 13,4\% en los municipios, los de capital han ganado participación durante las dos últimas décadas, hasta representar cerca del $86 \%$ tanto en los departamentos como en los municipios. En la reducción de la participación de los gastos corrientes han contribuido los gastos de funcionamiento y los de intereses de deuda pública.

\subsection{Ingresos propios, transferencias y regalías: una mirada en el agregado}

El enfoque ahora será en las tres principales fuentes de recursos de las entidades territoriales. La figura 3 muestra la dinámica que han tenido los ingresos 
propios (ingresos tributarios y no tributarios), las transferencias nacionales y las regalías, para el período 1984-2015, y en una comparación para el agregado de los departamentos y municipios.

En este caso se destaca la dinámica de las diferencias en los montos recaudados y recibidos por las dos entidades territoriales en un período de más de tres décadas. Lo primero que se observa es que mientras los departamentos han percibido mayores montos por concepto de regalías, diferencia que se amplió significativamente después de la reforma al Sistema General de Regalías (SGR) en 2012, los municipios han logrado durante casi todo el período de análisis mayores recaudos y mayores transferencias por parte del gobierno central.

Al observar la evolución de los ingresos propios, se puede ver un aumento constante en los montos recaudados para municipios y departamentos. Sin embargo, los municipios han venido ampliando la brecha desde 1993 en forma significativa y sistemática, hasta alcanzar una diferencia en cerca de 10 billones en 2015 .

Una historia similar, aunque con un punto de inicio posterior, es la diferencia que existe en los montos recibidos por las entidades territoriales por concepto de transferencias nacionales. Aunque los municipios siempre han estado por encima de los departamentos, entre 1995 y 2002 recibieron montos similares del gobierno central. A partir de 2003, momento en el que inició el SGP, los municipios se alejaron rápidamente de los departamentos, ampliando la brecha hasta alcanzar una diferencia cercana a los 12 billones en 2015. Si se considera el período 1996-2015, con el fin de hacer comparables estos con los resultados iniciales, y se calculan las tasas de crecimiento promedio anual para los períodos 1996-2001 y 2002-2015, los resultados son consistentes con lo observado anteriormente (figura 4).

En el caso de las transferencias, el crecimiento para departamentos y municipios fue similar, aunque levemente superior para los primeros. Posterior a la reforma a las transferencias, e inicio del SGP, mientras los recursos recibidos por los departamentos crecieron a una tasa del 2,8\% promedio anual, las transferencias de los municipios lo hicieron a una tasa del 7,4\%. En el caso de las regalías, estas han crecido en forma homogénea, no solo entre las dos entidades territoriales, sino a lo largo de los dos períodos de tiempo considerados. Lo que se observa, en general, es que es a partir de 2002 las regalías iniciaron un crecimiento sostenido debido al boom minero-energético.

Los resultados para los ingresos propios son también interesantes. Aquí hay una primera evidencia en contra de la pereza fiscal, ya que los resultados muestran que, si bien las transferencias y las regalías han crecido en ambos períodos de tiempo más rápidamente que los ingresos propios, estos últimos 

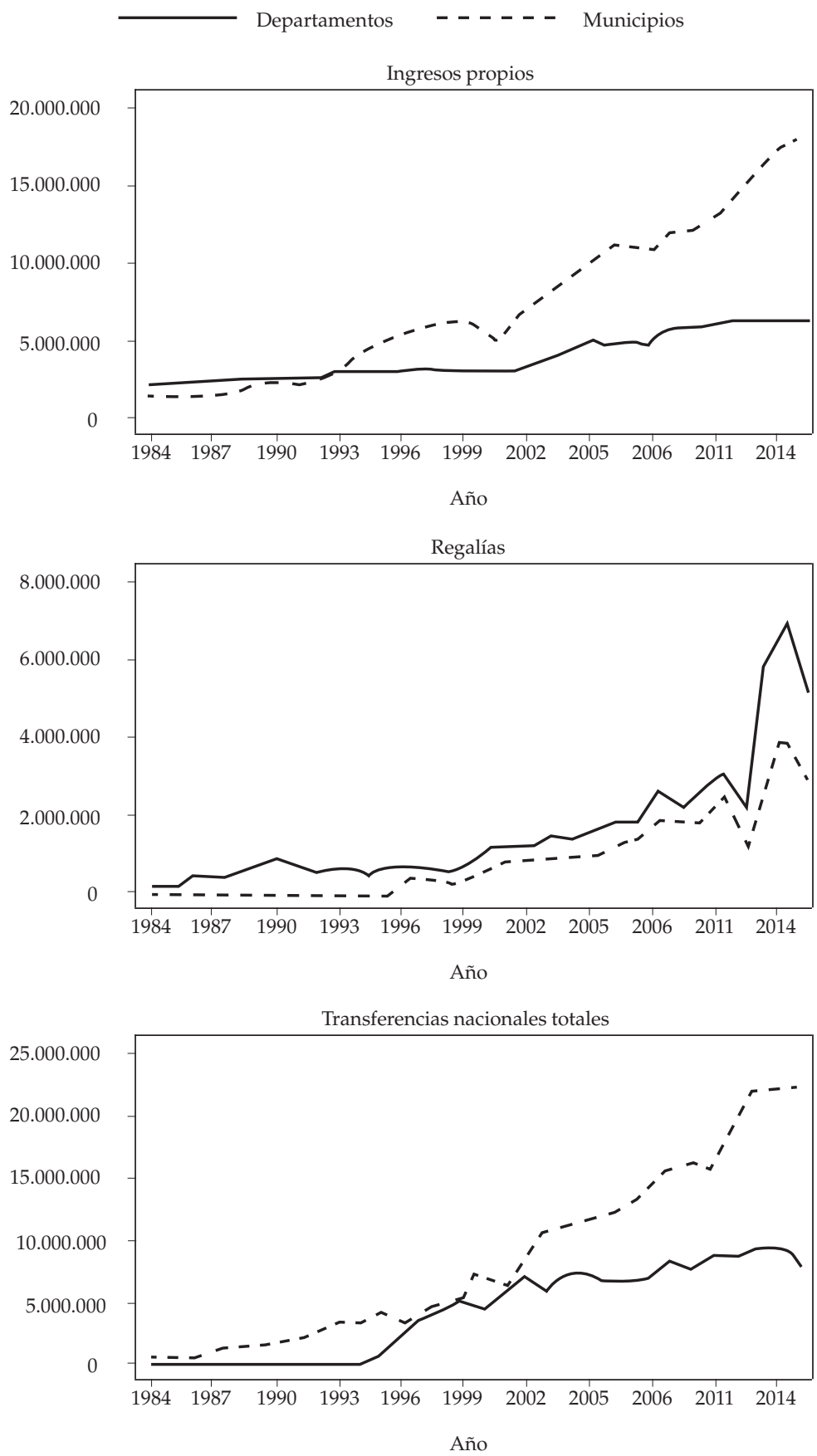

Figura 3. Ingresos propios, transferencias nacionales totales y regalías, 1984-2015 (Millones de pesos constantes de 2008)

Fuente: DNP. Elaboración de los autores. 
han aumentado su velocidad en el período 2002-2015 si se compara con el período 1996-2001. De hecho, los ingresos propios de los departamentos crecieron en el último período a una tasa nueve veces superior a la del primer período, y los municipios los hicieron casi cinco veces más rápido que en el período inicial.

a) Departamentos

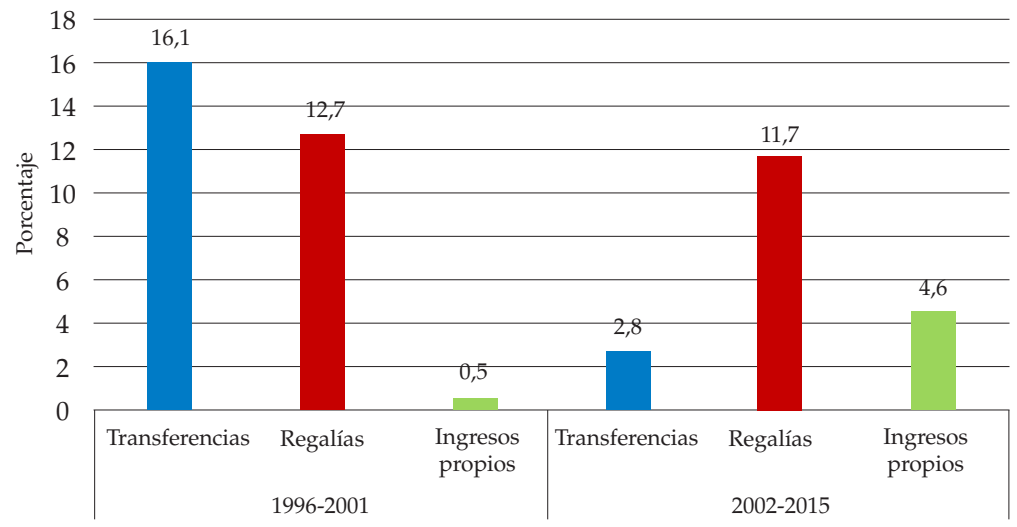

b) Municipios

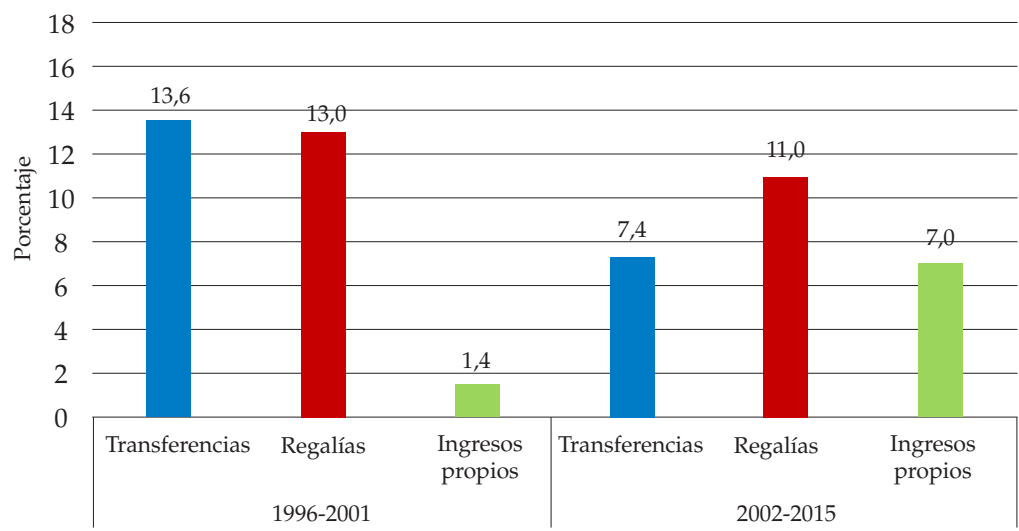

Figura 4. Crecimiento de los recursos de las entidades territoriales (Tasa de crecimiento promedio anual, 1996-2001 y 2002-2005)

Fuente: DNP. Ejecuciones presupuestales. Cálculos de los autores.

\subsection{Ingresos propios, transferencias y regalías: una mirada} por categorías de municipios y departamentos

Aunque de los resultados anteriores se puede tener una idea general acerca de lo que ha ocurrido durante las dos últimas décadas con las tres principales 
fuentes de ingreso de departamentos y municipios, también es cierto que estos son heterogéneos en sí mismos. Con el fin de tener en cuenta esta información en el análisis, la figura 5 muestra, para los departamentos (panel a) y para los municipios (panel b), una comparación para cada uno de los subgrupos en cada una de las tres fuentes de ingreso: ingresos propios, transferencias nacionales y regalías.

En cuanto a las regalías, el patrón más evidente para las dos entidades territoriales es el aumento en los montos recibidos a partir de 2013, con la creación del SGR. Los mayores incrementos se dieron en los municipios clasificados como 'resto', aquellos diferentes a las capitales y a los de mayor tamaño. La figura 6 ilustra los resultados de calcular las tasas de crecimiento de estas tres fuentes de ingreso para cada una de las anteriores categorías de departamentos (panel a) y municipios (panel b), y en dos períodos distintos (1996-2001 y 2002-2015), en donde no se percibe un patrón común temporal o por tamaño de la entidad territorial.

La característica más evidente es que, en la mayoría de casos, las transferencias y regalías mostraron tasas de crecimiento promedio anual superiores a los ingresos propios. Esto podría interpretarse como pereza fiscal solo en el caso en el que los ingresos propios tuvieran una tasa de crecimiento cercana a cero o, incluso, negativa. Sin embargo, este no es el caso, excepto para los departamentos clasificados como grandes y las capitales de departamento (en el caso de los municipios) en el período 1996-2001, momento en el que los ingresos propios crecieron a tasas negativas.

a) Departamentos

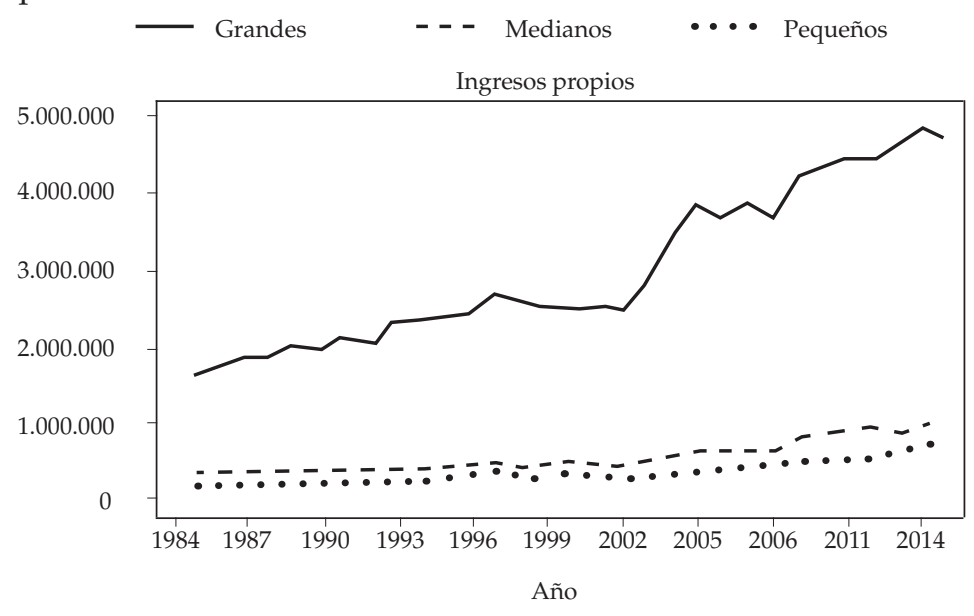




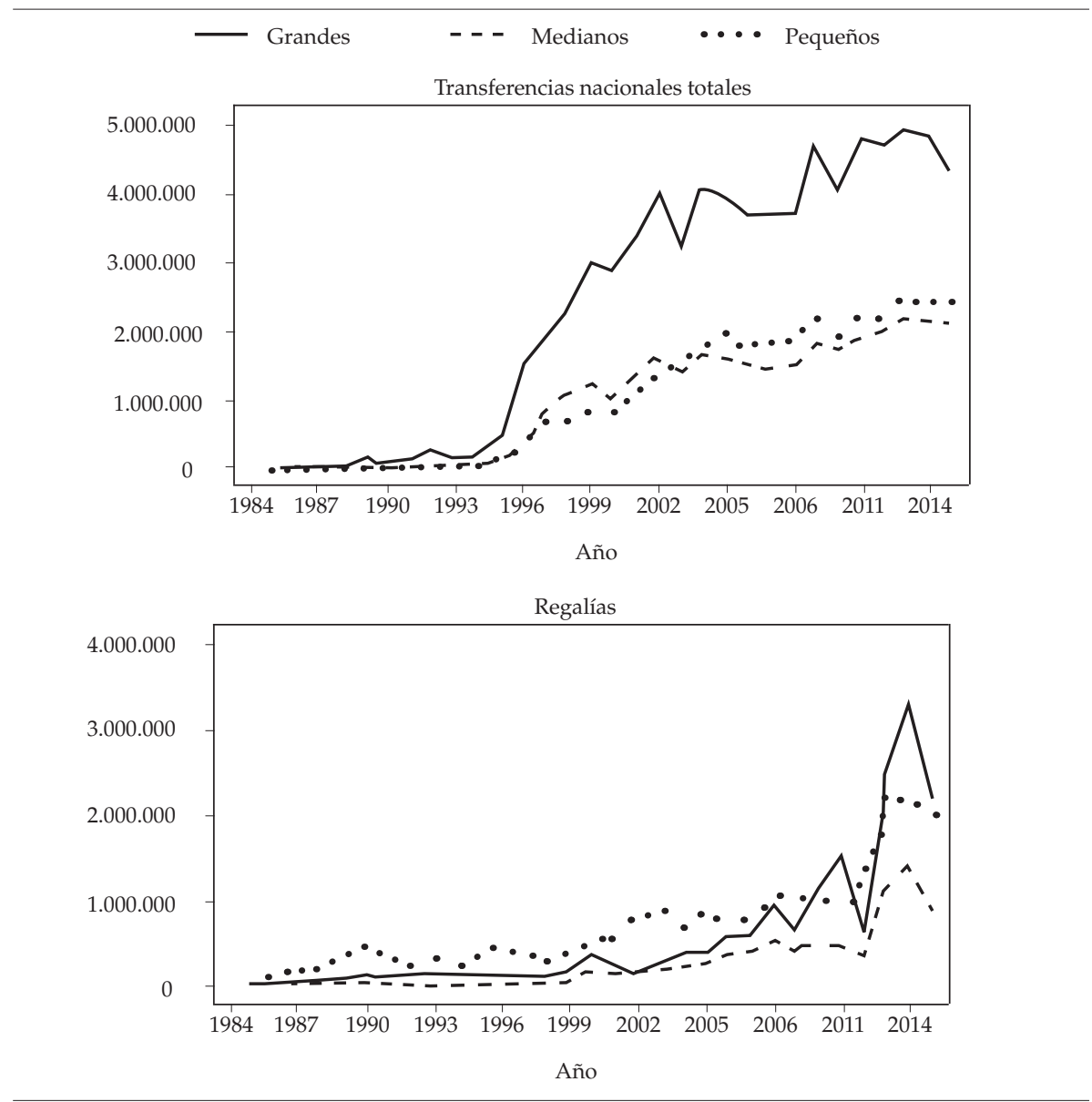

b) Municipios
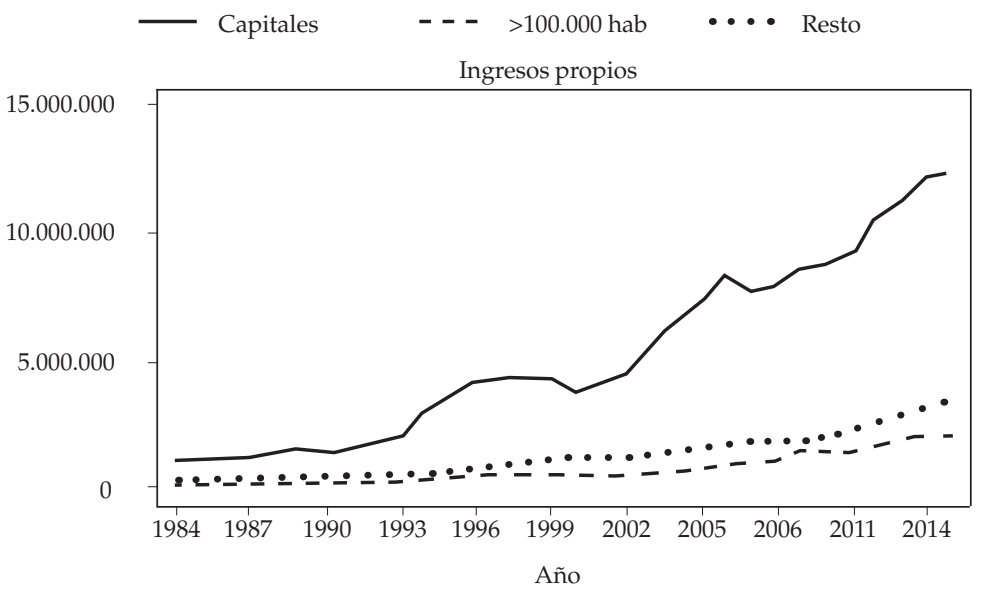

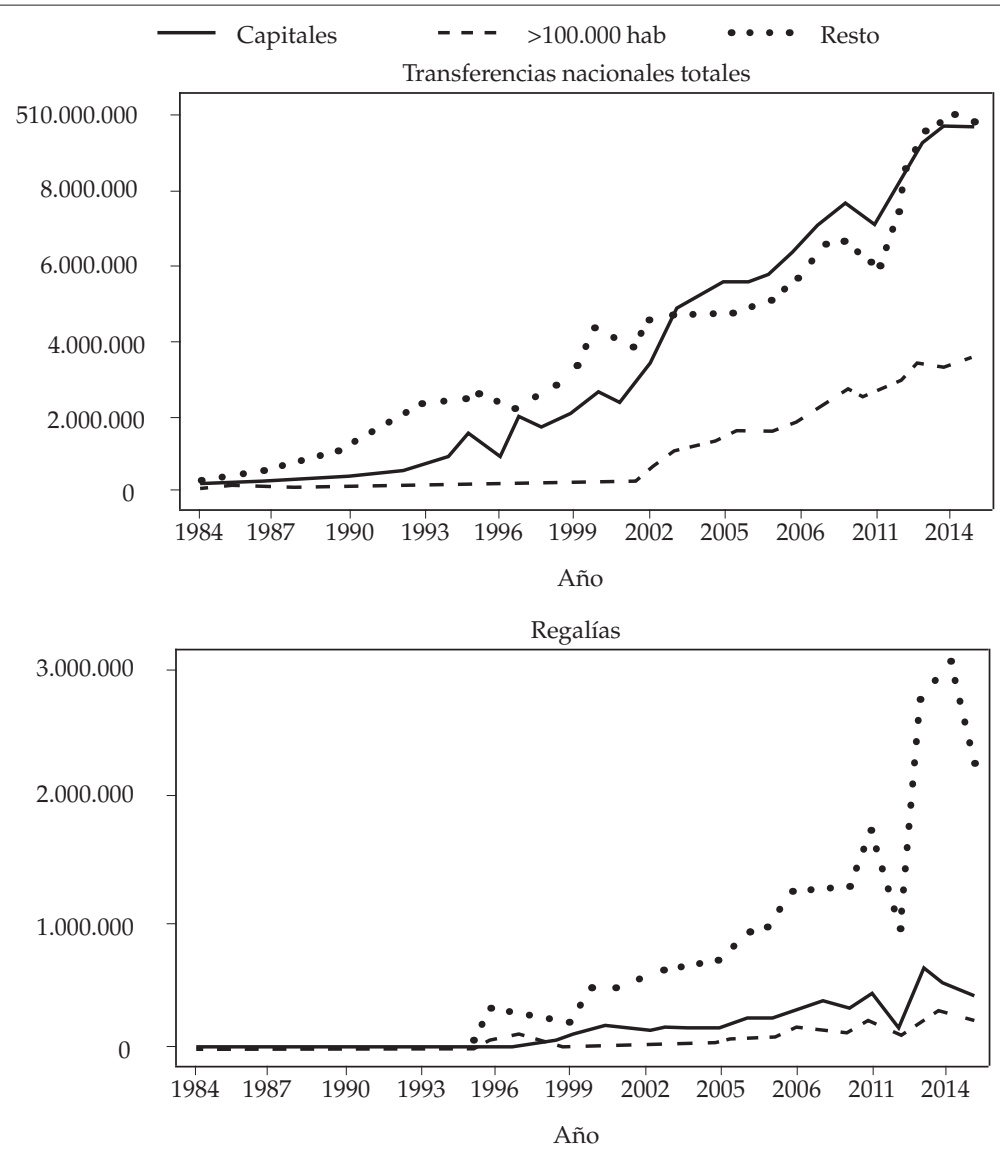

Figura 5. Ingresos propios, transferencias nacionales totales y regalías por categorías de municipios y departamentos (Millones de pesos constantes de 2008, 1984-2015)

Nota: Los departamentos fueron clasificados siguiendo los criterios establecidos por la Contaduría General de la Nación y el Ministerio del Interior, en particular la Resolución 679 del 28 de noviembre de 2016. De acuerdo con estos, se clasificaron los departamentos así: grandes: Antioquia, Cundinamarca, Valle, Atlántico, Bolívar, Santander, Boyacá, Córdoba, Nariño y Meta; medianos: Cesar, Huila, Risaralda, Caldas, Magdalena, Norte de Santander y Tolima; pequeños: Cauca, Quindío, Arauca, Casanare, Guaviare, Vichada, Caquetá, Chocó, La Guajira, Sucre, Putumayo, San Andrés, Amazonas, Guainía y Vaupés.

Fuente: DNP. Ejecuciones presupuestales. Cálculos de los autores. 
a) Departamentos

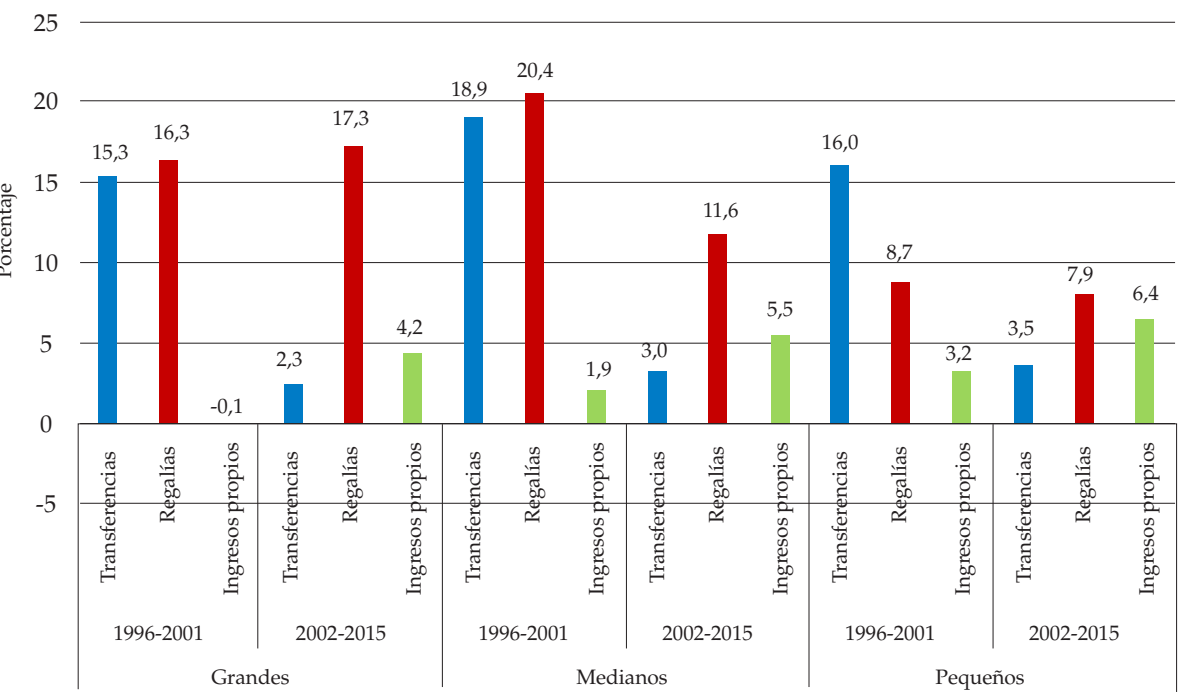

b) Municipios

25

20

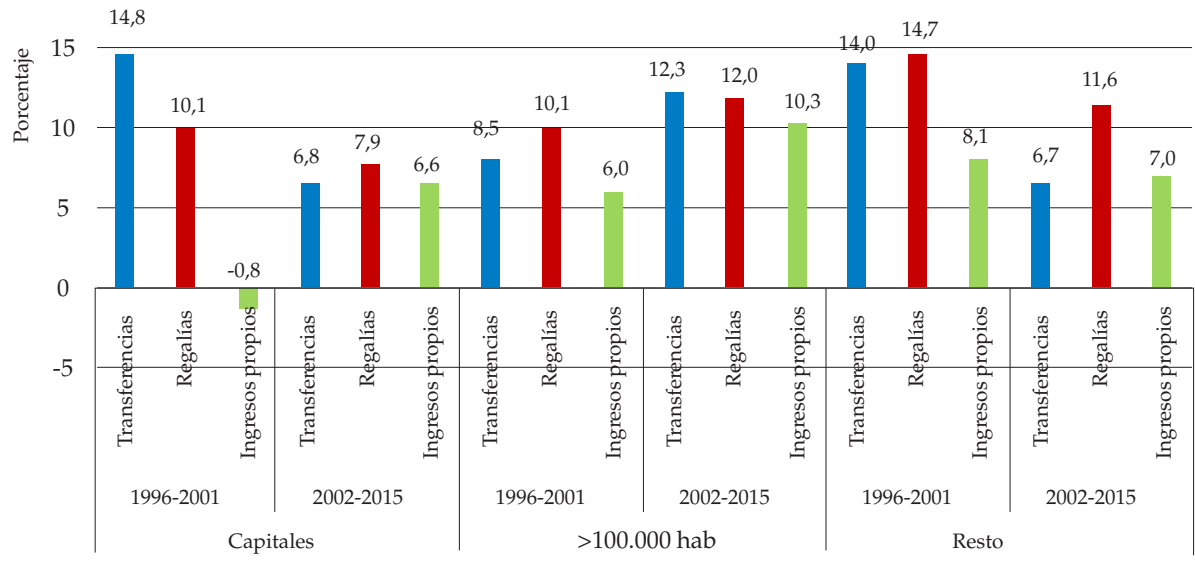

Figura 6. Crecimiento de los recursos de las entidades territoriales por categorías (Tasa de crecimiento promedio anual, 1996-2001 y 2002-2015)

Nota: Los departamentos fueron clasificados siguiendo los criterios establecidos por la Contaduría General de la Nación y el Ministerio del Interior, en particular la Resolución 679 del 28 de noviembre de 2016. De acuerdo con estos, se clasificaron los departamentos así: grandes: Antioquia, Cundinamarca, Valle, Atlántico, Bolívar, Santander, Boyacá, Córdoba, Nariño y Meta; medianos: Cesar, Huila, Risaralda, Caldas, Magdalena, Norte de Santander y Tolima; pequeños: Cauca, Quindío, Arauca, Casanare, Guaviare, Vichada, Caquetá, Chocó, La Guajira, Sucre, Putumayo, San Andrés, Amazonas, Guainía y Vaupés.

Fuente: DNP. Ejecuciones presupuestales. Cálculos de los autores. 
En los demás casos, las tasas de crecimiento de esta fuente de ingreso fueron altas, especialmente para los departamentos, los cuales alcanzaron crecimientos de más del $10 \%$ promedio anual en algunos casos. De modo que no es posible afirmar, al menos a través de estas evidencias, que la descentralización fiscal en Colombia haya promovido la pereza fiscal de los GSN.

\subsection{Una mirada a los indicadores fiscales de las entidades territoriales}

A manera de síntesis del estado general de los gsn en Colombia durante las dos últimas décadas, se presenta un resumen de los principales indicadores fiscales para los tres momentos del tiempo considerados: 1996, 2001 y 2015. La tabla 3 expone estos resultados para los departamentos (panel a) y para los municipios (panel b). ${ }^{5}$

Tabla 3. Indicadores fiscales de las entidades territoriales

a) Gobiernos departamentales

\begin{tabular}{|c|c|c|c|}
\hline Indicadores de ahorro & 1996 & 2001 & 2015 \\
\hline Ahorro primario (millones de pesos constantes de 2008) & 1.055 .400 & 1.431 .144 & 3.404 .938 \\
\hline Ahorro operacional (millones de pesos constantes de 2008) & 646.918 & 1.074 .999 & 3.241 .508 \\
\hline Ahorro total (millones de pesos constantes de 2008) & 3.844 .157 & 8.715 .252 & 18.566 .640 \\
\hline Capacidad de ahorro (\%) & 19,3 & 31,4 & 48,3 \\
\hline Indicadores de ingreso & 1996 & 2001 & 2015 \\
\hline Importancia de impuesto a la cerveza (\%) & 22,7 & 23,0 & 22,7 \\
\hline Importancia de impuesto a los licores (\%) & 24,2 & 22,7 & 11,5 \\
\hline Importancia de impuesto a los cigarrillos (\%) & 5,8 & 9,9 & 5,1 \\
\hline Importancia de impuesto de registro (\%) & 6 & 6,5 & 11,5 \\
\hline Importancia de impuesto de vehículos (\%) & 5,2 & 6,5 & 6,3 \\
\hline Importancia de la sobretasa a la gasolina (\%) & 0,0 & 5,5 & 4,4 \\
\hline Dependencia de transferencias (\%) & 33,4 & 51,8 & 39,4 \\
\hline Indicadores de gasto & 1996 & 2001 & 2015 \\
\hline $\begin{array}{l}\text { Participación de los gastos de funcionamiento en el gasto } \\
\text { total }(\%)\end{array}$ & 35,9 & 20,0 & 13,4 \\
\hline $\begin{array}{l}\text { Participación de los gastos de personal en los gastos de } \\
\text { funcionamiento }(\%)\end{array}$ & 39,3 & 58,0 & 25,1 \\
\hline
\end{tabular}

5 El anexo 1 presenta las definiciones de cada uno de los indicadores de ahorro, ingreso y gasto. 


\begin{tabular}{lrrr} 
Capacidad de financiación de los gastos total (\%) & 68,4 & 58,2 & 49,2 \\
Participación de la inversión de los gastos total (\%) & 57,7 & 76,5 & 85,9 \\
Autofinanciación de la inversión (\%) & 45,0 & 39,0 & 46,8 \\
Inversión financiada por transferencia (\%) & 59,3 & 75,0 & 41,0 \\
Participación de los intereses en el gasto total (\%) & 6,4 & 3,6 & 0,7 \\
\hline
\end{tabular}

b) Gobiernos municipales

\begin{tabular}{|c|c|c|c|}
\hline Indicadores de ahorro & 1996 & 2001 & 2015 \\
\hline Ahorro primario (millones de pesos constantes de 2008) & 2.925 .621 & 2.276 .929 & 12.674 .504 \\
\hline Ahorro operacional (millones de pesos constantes de 2008) & 1.048 .073 & 1.697 .713 & 12.275 .661 \\
\hline Ahorro total (millones de pesos constantes de 2008) & 6.953 .003 & 10.691 .097 & 42.756 .468 \\
\hline Capacidad de ahorro (\%) & 17,1 & 26,1 & 63,6 \\
\hline Indicadores de ingreso & 1996 & 2001 & 2015 \\
\hline Capacidad de generación de ingresos permanentes (\%) & 50,9 & 42,0 & 38,8 \\
\hline Importancia del ICA (\%) & 27,8 & 29,6 & 30,1 \\
\hline Importancia del predial (\%) & 23,4 & 25,3 & 26,1 \\
\hline Dependencia de las transferencias (\%) & 23,5 & 38,6 & 43,1 \\
\hline Importancia de los ingresos capital (\%) & 48,1 & 58 & 61,2 \\
\hline Indicadores de gasto & 1996 & 2001 & 2015 \\
\hline $\begin{array}{l}\text { Participación de los gastos de funcionamiento en el gasto } \\
\text { total (\%) }\end{array}$ & 20,6 & 25,6 & 12,6 \\
\hline $\begin{array}{l}\text { Participación de los gastos de personal en los gastos de } \\
\text { funcionamiento }(\%)\end{array}$ & 53,3 & 49,2 & 39,5 \\
\hline Capacidad de financiación de los gastos funcionamiento (\%) & 52,1 & 65,0 & 34,3 \\
\hline Participación de la inversión de los gastos total (\%) & 62,5 & 70,9 & 86,6 \\
\hline Autofinanciación de la inversión (\%) & 42,8 & 40,2 & 46,8 \\
\hline Inversión financiada por transferencia (\%) & 29,2 & 51,0 & 47,2 \\
\hline Participación de los intereses en el gasto total (\%) & 12,1 & 3,5 & 0,8 \\
\hline
\end{tabular}

Fuente: DNP. Ejecuciones presupuestales. Cálculos de los autores.

Algunas de las características que se destacan es que la capacidad de ahorro ha aumentado tanto para municipios como para departamentos, lo cual es una buena noticia si se tiene en cuenta que esto les permite a las entidades territoriales tener no solo un mayor flujo de caja, sino incrementar su capacidad de endeudamiento. En cuanto a las transferencias, mientras los municipios han tendido a aumentar la dependencia de estos recursos durante el período de análisis, los departamentos muestran una tendencia decreciente. 
También común a municipios y departamentos es el hecho de que la participación de los gastos de funcionamiento ha tenido una tendencia a la baja, aunque igualmente ha ocurrido con la capacidad de financiar dichos gastos. En general, al menos para el agregado, los resultados parecen ser positivos, especialmente en términos de ahorro y de autofinanciación de la inversión, la cual ha presentado una variación positiva en los últimos años. Las tendencias completas año a año de cada uno de estos indicadores se pueden ver en el anexo 2.

\section{Revisión de la pereza fiscal}

Diversas metodologías han sido usadas para estimar los efectos de incrementos en las transferencias sobre la generación de recursos propios de las entidades territoriales en Colombia. Cadena (2002) usó la evolución de los ingresos subnacionales antes y después de la Constitución de 1991 para estimar un modelo de dobles diferencias y medir el efecto del aumento en las transferencias sobre los ingresos tributarios de los municipios. Por su parte, Perry y Olivera (2009) utilizaron un modelo de datos panel para estimar el mismo efecto, en este caso para el período comprendido entre 1990 y 2008. Más recientemente, Ramírez y Bedoya (2014) usaron un modelo con efectos fijos y un panel dinámico para estimar el efecto de las regalías directas por hidrocarburos sobre el recaudo de impuesto predial para el período comprendido entre 2004 y 2011.

A diferencia de los trabajos anteriores, este documento distingue entre los efectos de tres reformas importantes que aumentaron el monto de recursos transferidos a municipios y departamentos: la creación del situado fiscal y las participaciones municipales con la Constitución de 1991, la reforma al SGP con la Ley 715 de 2001 y la creación del nuevo sGR con la Ley 1530 de 2012. Para probar empíricamente si estas reformas se convirtieron en una fuente de pereza fiscal en los municipios colombianos, se usan dos métodos distintos. El primero es el modelo de dobles diferencias aplicado en Cadena (2002), el cual resulta especialmente útil para evaluar los efectos de cada reforma de manera independiente. Esta aproximación se complementa con un modelo de efectos fijos para datos panel, el cual, además de identificar los cambios estructurales generados por cada reforma, permite incluir características no observables de los municipios, controlando así el alto grado de heterogeneidad que se presume en la muestra, algo que no se tiene en cuenta en la primera aproximación. 


\subsection{Modelo de dobles diferencias}

La estimación del modelo considera el período anterior y posterior de la entrada en vigencia de los cambios que plantea cada reforma, operando el primero como un contrafactual que permite ver cómo habría sido la evolución de las variables sin la reforma, mientras que el segundo captura el cambio en el crecimiento luego de la transformación del sistema. Al incluir únicamente los cambios observados en el crecimiento de las variables, se eliminan los niveles de crecimiento propios de cada municipio y con ello se evita la inclusión de relaciones espurias, un problema característico de estimaciones como esta, en donde existe una alta correlación entre las variables de interés.

Para este modelo, los crecimientos de las variables son definidos como proporción de los ingresos propios en el período inicial, viéndose representados de la siguiente forma:

$$
\begin{aligned}
\Delta \operatorname{IngTri} i_{i}\left(t_{1}, t_{2}\right) & =\left[\frac{\operatorname{ing} \operatorname{Tr} i_{i t 2}-\operatorname{IngTr} i_{i t 1}}{\operatorname{Ing} \operatorname{Pr} o_{i t 1}}\right] /\left(t_{2}-t_{1}\right) \\
\Delta \operatorname{Transf}_{i}\left(t_{1}, t_{2}\right) & =\left[\frac{\operatorname{Transf}_{i t 2}-\operatorname{Transf} f_{i t 1}}{\operatorname{Ing} \operatorname{Pr} o_{i t 1}}\right] /\left(t_{2}-t_{1}\right) \\
\Delta \operatorname{Re} g_{i}\left(t_{1}, t_{2}\right) & =\left[\frac{\operatorname{Re} g_{i t 2}-\operatorname{Re} g_{i t 1}}{\operatorname{Ing} \operatorname{Pr} o_{i t 1}}\right] /\left(t_{2}-t_{1}\right)
\end{aligned}
$$

Donde IngTri, IngPro, Transf y Reg hacen referencia a los ingresos tributarios, los ingresos propios, las transferencias y las regalías, respectivamente. El subíndice $i$ hace referencia al municipio. Por último, $t_{1}$ y $t_{2}$ son los años inicial y final que dependen de la reforma que se esté analizando. ${ }^{6}$

Tomando los crecimientos en (1), (2) y (3), el modelo de dobles diferencias puede verse representado de la siguiente forma:

$$
\begin{gathered}
\Delta \operatorname{IngTri}\left(t_{1}, t_{2}\right)_{i}^{\text {Post }}-\Delta \operatorname{IngTri}\left(t_{1}, t_{2}\right)_{i}^{\mathrm{Pre}}=\alpha+\beta\left[\Delta \operatorname{Transf}\left(t_{1}, t_{2}\right)_{i}^{\text {Post }}-\right. \\
\left.\Delta \operatorname{Transf}\left(t_{1}, t_{2}\right)_{i}^{\mathrm{Pre}}\right]+v_{i}
\end{gathered}
$$

6 El uso de un denominador común para el cálculo de los crecimientos tiene como propósito dejar de lado las diferencias preexistentes en los niveles de las variables por analizar. 


$$
\begin{gathered}
\Delta \operatorname{IngTri}\left(t_{1}, t_{2}\right)_{i}^{\text {Post }}-\Delta \operatorname{IngTri}\left(t_{1}, t_{2}\right)_{i}^{\text {Pre }}=\alpha+\beta\left[\Delta \operatorname{Re} g\left(t_{1}, t_{2}\right)_{i}^{\text {Post }}-\right. \\
\left.\Delta \operatorname{Reg}\left(t_{1}, t_{2}\right)_{i}^{\text {Pre }}\right]+v_{i}
\end{gathered}
$$

Donde $\beta$ es el parámetro de interés que captura el efecto de un cambio en la tendencia de las transferencias o regalías sobre la tendencia de los ingresos tributarios. ${ }^{7}$ Los años inicial y final, expresados como $t_{1}$ y $t_{2}$, se muestran con mayor detalle en la tabla 4. Estos años se definen teniendo en cuenta el momento a partir del cual comienzan a regir los cambios introducidos por las reformas y con el objetivo de aislar una reforma de otra.

Tabla 4. Años usados para el cálculo de crecimientos

\begin{tabular}{lcc}
\hline & Pre-reforma & Post-reforma \\
\hline Situado fiscal y part. municipales & $t_{1}=1984, t_{2}=1992$ & $t_{1}=1993, t_{2}=2000$ \\
SGP & $t_{1}=1994, t_{2}=2001$ & $t_{1}=2002, t_{2}=2011$ \\
SGR & $t_{1}=2003, t_{2}=2011$ & $t_{1}=2012, t_{2}=2014$ \\
\hline
\end{tabular}

Fuente: elaboración de los autores.

Tomando como referencia los años presentados en la tabla 4 y usando las definiciones en (1), (2) y (3), se calculan los crecimientos anuales de transferencias, ingresos tributarios y regalías para cada uno de los municipios de la muestra. La tabla 5 presenta un promedio simple de los crecimientos resultantes para cada uno de los períodos analizados.

En el caso de la primera reforma, que abarca los períodos 1984-1992 y 19932000, vemos un cambio de 19 puntos porcentuales (pp) en el crecimiento de las transferencias en municipios, el cual vino acompañado de una variación menor (4 pp) en el crecimiento de los ingresos tributarios. Seguido de esto, en la reforma que crea el SGP, también se observa un cambio positivo en el crecimiento de los ingresos tributarios, a pesar de la caída en el crecimiento de las transferencias durante este período. Por último, en los períodos 20032011 y 2012-2014, es evidente una variación positiva en el crecimiento de las regalías. Para este último caso y a pesar de que el aumento en el crecimiento de las regalías es de casi 50 pp durante este período, la variación en el crecimiento de los ingresos tributarios es únicamente de $2 \mathrm{pp}$. Estas tendencias son similares a las observadas en los departamentos (anexo 3).

7 Los ingresos tributarios corresponden al $87 \%$ de los ingresos propios en municipios. 
Tabla 5. Crecimiento anual de transferencias e ingresos tributarios, promedio municipios

(Porcentajes)

\begin{tabular}{|c|c|c|}
\hline & Pre-Reforma & Post-Reforma \\
\hline \multicolumn{3}{|c|}{ Reforma 1: Situado Fiscal y part. Municipales } \\
\hline & 1984-1992 & 1993-2000 \\
\hline Transferencias & 190,7 & 209,6 \\
\hline Ingresos Tributarios & 10,1 & 14,2 \\
\hline Predial & 6 & 3,6 \\
\hline ICA & 1,8 & 2,7 \\
\hline Otros impuestos & 2,2 & 8,5 \\
\hline \multicolumn{3}{|c|}{ Reforma 2: SGP } \\
\hline & 1994-2001 & 2002-2011 \\
\hline Transferencias & 159,7 & 46,5 \\
\hline Ingresos Tributarios & 14,2 & 18,4 \\
\hline Predial & 3,2 & 3,4 \\
\hline ICA & 2,3 & 3,8 \\
\hline Otros impuestos & 9,3 & 11,1 \\
\hline \multicolumn{3}{|c|}{ Reforma 3: SGR } \\
\hline & 2003-2011 & 2012-2014 \\
\hline Transferencias & 42,3 & 91,1 \\
\hline Ingresos Tributarios & 20,2 & 22,4 \\
\hline Predial & 3 & 2,2 \\
\hline ICA & 4,1 & 3,9 \\
\hline Otros impuestos & 13,1 & 16,3 \\
\hline
\end{tabular}

Nota: Los crecimientos aquí definidos se calculan como proporción de los ingresos propios en el período inicial. Fuente: cálculos de los autores con datos del DNP.

Si se examina el papel de los principales impuestos dentro del agregado, se encuentra que la contribución de cada uno al crecimiento de los ingresos tributarios ha variado a través del tiempo. Por un lado, se destaca el dinamismo del ICA, que mostró cambios positivos en su crecimiento en los períodos posteriores a las primeras dos reformas. El predial, en contraste, solo muestra una variación positiva en el período posterior a la reforma que crea el SGP.

En términos generales y con base en estos promedios, no existen indicios de pereza fiscal en las entidades territoriales para ninguno de los períodos analizados, ya que los ingresos tributarios crecen a la par del aumento en los 
recursos transferidos. Sin embargo, sí parece ser que la magnitud del esfuerzo fiscal ha sido diferencial entre reformas, siendo mayor para el caso del aumento en las transferencias y menor para el caso del incremento en las regalías. Además, se encuentra que en general el esfuerzo recaudatorio es menor que el cambio en transferencias, indicando incrementos de distinta magnitud.

Luego de revisar la evolución de las transferencias y los ingresos tributarios de los municipios en la muestra, la tabla 6 expone los resultados de las estimaciones del modelo de dobles diferencias —ecuaciones (4) y (5)—. Las variables usadas en estas primeras estimaciones son los ingresos tributarios y las transferencias.

Tabla 6. Resultados modelo dobles diferencias

(Variable dependiente: ingresos tributarios)

\begin{tabular}{|c|c|}
\hline \multicolumn{2}{|c|}{ Reforma 1: Situado Fiscal y part. Municipales } \\
\hline \multirow{2}{*}{ Transferencias } & $0,036^{* * *}$ \\
\hline & $(0,009)$ \\
\hline \multirow{2}{*}{ Constante } & $0,034^{* * *}$ \\
\hline & $(0,013)$ \\
\hline Observaciones & 891 \\
\hline \multicolumn{2}{|c|}{ Reforma 2: SGP } \\
\hline \multirow{2}{*}{ Transferencias } & $0,011^{*}$ \\
\hline & $(0,006)$ \\
\hline \multirow{2}{*}{ Constante } & 0,018 \\
\hline & $(0,013)$ \\
\hline Observaciones & 916 \\
\hline \multicolumn{2}{|c|}{ Reforma 3: SGR } \\
\hline \multirow{2}{*}{ Transferencias } & $0,066^{* * *}$ \\
\hline & $(0,011)$ \\
\hline \multirow{2}{*}{ Constante } & $-0,018$ \\
\hline & $(0,025)$ \\
\hline Observaciones & 1.072 \\
\hline
\end{tabular}

Nota: Los modelos son estimados por mínimos cuadrados ordinarios. Errores estándar robustos en paréntesis. $*, * *, * *$ indican niveles de significancia del $10 \%, 5 \%$ y $1 \%$, respectivamente.

Fuente: cálculos de los autores con datos del DNP.

Conforme con los resultados, en ningún caso parece haber evidencia de pereza fiscal. Todos los coeficientes resultan positivos y significativos. El cambio en las transferencias en el período 1993-2000 tuvo un efecto en el crecimiento 
de los ingresos tributarios de 0,036. Para el período 2002-2011 este coeficiente alcanza un valor de 0,011 y para el caso de las regalías el efecto es de 0,066.

Es importante aclarar que estas primeras estimaciones pueden presentar limitaciones debido a la posible influencia de choques externos que afectan a las variables, pero que no son capturados por el modelo. En particular, y siguiendo a Ramírez y Bedoya (2014), el coeficiente de esfuerzo fiscal podría estar sobreestimado en el caso de las regalías. Estos autores argumentan que la relación de impuestos como el ICA con la explotación de hidrocarburos en los territorios podría ser fuente de problemas de endogeneidad en el modelo.

Para superar esta crítica, se realizó un segundo ejercicio tomando únicamente los ingresos tributarios provenientes del predial. Este último tributo es menos dependiente de la dinámica económica y, por ende, un mejor indicador de esfuerzo fiscal propio. Adicionalmente, se incluyeron dos variables dicotómicas ( Capitales y 100Hab ), las cuales permiten diferenciar los municipios capitales y con más de 100 mil habitantes del resto de municipios. Como puede verse en la tabla 7 , los coeficientes siguen siendo positivos y significativos, aunque de menor magnitud que los encontrados en el ejercicio anterior. Para el caso particular de las regalías, el coeficiente resulta bastante menor, pasando de 0,066 a 0,003. Por último y para las reformas 1 y 2 , los coeficientes se reducen a 0,014 y 0,004 , respectivamente.

En términos generales, estos primeros resultados muestran que las reformas ocurridas en las últimas décadas no han sido una fuente de pereza fiscal en las entidades territoriales. El crecimiento en las transferencias se ha relacionado con un crecimiento del recaudo tributario, a pesar de que estos últimos resultan ser mínimos. Además, las estadísticas revelan que el esfuerzo fiscal ha sido diferencial entre reformas, siendo mayor para el caso de las transferencias y menor para el aumento en regalías.

Tabla 7. Resultados modelo dobles diferencias

(Variable dependiente: ingresos por predial)

\begin{tabular}{lc}
\hline \multicolumn{2}{c}{ Refroma 1: Situado Fiscal y part. Minucipales } \\
\hline Transferencias & $0,014^{* * *}$ \\
& $(0,004)$ \\
Capitales & $0,040^{* * *}$ \\
100Hab & $(0,014)$ \\
& 0,002 \\
Constante & $(0,014)$ \\
& $-0,026^{* * *}$ Continúa
\end{tabular}


Observaciones

\begin{tabular}{lr} 
& 884 \\
\hline Transferencias & $0,014^{* * *}$ \\
& $(0,002)$ \\
Capitales & 0,001 \\
100Hab & $(0,008)$ \\
Constante & 0,003 \\
& $(0,010)$ \\
Observaciones & $-0,006$ \\
& $(0,004)$ \\
\hline
\end{tabular}

Reforma 3: SGR

Transferencias

Capitales

$100 \mathrm{Hab}$

Constante

Observaciones
$(0,007)$

884

$(0,002)$

$(0,008)$

$(0,004)$

909

\begin{tabular}{lc}
\hline \multicolumn{2}{c}{ Reforma 3: SGR } \\
\hline Transferencias & $0,003^{* *}$ \\
& $(0,001)$ \\
Capitales & $0,020^{* *}$ \\
100Hab & $(0,009)$ \\
& $0,047^{* * *}$ \\
Constante & $(0,017)$ \\
& $-0,014^{* * *}$ \\
Observaciones & $(0,004)$ \\
\end{tabular}

Nota: Los modelos son estimados por mínimos cuadrados ordinarios. Errores estándar robustos en paréntesis. $*, * *, * *$ indican niveles de significancia del $10 \%, 5 \%$ y $1 \%$, respectivamente.

Fuente: cálculos de los autores con datos del DNP.

\subsection{Modelo de efectos fijos}

A diferencia del modelo anterior, en esta estimación se utiliza un panel de datos con información de municipios para el período comprendido entre 1985 y 2015. A través de la inclusión de cambios estructurales en el modelo, el ejercicio estudia los efectos de cada reforma sobre el esfuerzo fiscal en las entidades de la muestra. Adicionalmente, la metodología identifica la relación entre los aumentos en transferencias y regalías y el recaudo tributario en todo el período. En particular, el estimador de efectos fijos permite calcular dicha relación controlando por características no observables en los municipios, que 
son constantes en el tiempo, pero que pueden influir en el esfuerzo tributario observado. Por último y para evitar posibles problemas de endogeneidad, la variable dependiente del modelo será el recaudo por impuesto predial. Todas estas particularidades se incluyen en la siguiente representación del modelo:

$$
\begin{aligned}
& \text { Ln(Predial) }{ }_{i t}=\alpha+\beta_{1} \operatorname{Ln}_{(\text {Transf })_{i t}}+\beta_{2} \operatorname{Ln}(\text { Reg })_{i t}+\theta_{I} \text { SituadoYParticip }_{i t}+\theta_{2} \\
& S G P_{i t}+\theta_{3} S_{G} R_{i t}+\delta_{1} \text { Capitales }^{*} \text { Transf }_{i t}+\delta_{2} 100 \text { Hab }^{*} \text { Transf }_{i t} \\
& +\delta_{3} \text { Capital }^{*} \operatorname{Reg}_{i t}+\delta_{4} 100 \mathrm{Hab}^{*} \operatorname{Reg}_{i t}+\delta_{5} \operatorname{Ln}_{(\text {Otros_Imp })_{i t}}+\delta_{6} \\
& \text { Ln(Poblacion) it }+v_{i t} \\
& \text { Con } v_{i t}=u_{i}+e_{i t}
\end{aligned}
$$

Donde $\operatorname{Ln}\left(\right.$ Predial) ${ }_{i t}$ Ln(Transf) ${ }_{i t}$ y $\operatorname{Ln}(\text { Reg })_{i t}$ hacen referencia al logaritmo del predial, las transferencias y las regalías para el municipio $i$, en el año $t$, respectivamente. SituadoYParticip, $S G P, S G R$ son variables dicotómicas que permiten evaluar la existencia de un cambio estructural luego de las principales reformas a los sistemas de transferencias y regalías. La variable Situado Y Particip toma el valor de 1 si las variables pertenecen al período posterior a dicha reforma (1993-2001). Para el caso de $S G P$ y $S G R$, estas toman un valor de 1 durante el período 2002-2011, en el primer caso, y durante el período 2012-2015, en el segundo. Las variables Capitales y $100 \mathrm{Hab}$ son variables dicotómicas que hacen referencia a municipios capitales y municipios con más de 100 mil habitantes, respectivamente. A partir de estas se construyen una serie de interacciones (Capitales * Transf, 100Hab * Transf, Capital * Reg, 100Hab * Reg), las cuales permiten diferenciar los efectos del aumento en transferencias y regalías entre las distintas categorías de municipios. Por su parte, Ln(Otros_Imp) representa el recaudo por concepto de otros impuestos, que captura en cierta medida los cambios de la actividad económica. La variable $L n$ (Poblacion) hace referencia a la población en el municipio y, por último, el término de error $v_{i t}$ se descompone entre un efecto fijo no observable $\left(u_{i}\right) \mathrm{y}$ un error aleatorio $\left(e_{i t}\right)$.

La tabla 8 indica los resultados obtenidos en la estimación de este modelo. Los coeficientes de las variables de interés tienen los signos esperados y resultan significativos. En primer lugar, se encuentra que aumentos del 1\% en las transferencias se asocian con incrementos del predial entre el 0,20\% y $0,25 \%$. Posteriormente y similar a los resultados de la tabla 8 de la sección anterior, el esfuerzo tributario es menor por el lado de las regalías que de las transferencias. En particular, un aumento del $1 \%$ en las regalías tiene un efecto sobre el recaudo del predial que oscila entre el $0,02 \%$ y $0,01 \%$. 
Tabla 8. Resultados modelo de efectos fijos

\begin{tabular}{|c|c|c|c|c|c|}
\hline \multicolumn{6}{|c|}{ Panel con efectos fijos } \\
\hline Log(Predial) & (1) & (2) & (3) & (4) & (5) \\
\hline \multirow{2}{*}{ Log(Transf) } & $0,25^{* * *}$ & $0,23^{* * *}$ & $0,23^{* * *}$ & $0,22^{* * *}$ & $0,20^{* * *}$ \\
\hline & $(0,017)$ & $(0,017)$ & $(0,016)$ & $(0,017)$ & $(0,016)$ \\
\hline \multirow{2}{*}{$\log (\operatorname{Reg})$} & $0,02^{* * *}$ & $0,02^{* * *}$ & $0,01^{* * *}$ & $0,01^{* * *}$ & 0,00 \\
\hline & $(0,003)$ & $(0,003)$ & $(0,003)$ & $(0,003)$ & $(0,003)$ \\
\hline \multirow{2}{*}{ SituadoyParticip } & $0,42^{* * *}$ & $0,45^{* * *}$ & $0,45^{* * *}$ & $0,43^{* * *}$ & $0,43^{* * *}$ \\
\hline & $(0,026)$ & $(0,025)$ & $(0,025)$ & $(0,025)$ & $(0,024)$ \\
\hline \multirow{2}{*}{ SGP } & $0,79^{* * *}$ & $0,81^{* * *}$ & $0,81^{* * *}$ & $0,68^{* * *}$ & $0,72^{* * *}$ \\
\hline & $(0,035)$ & $(0,034)$ & $(0,034)$ & $(0,034)$ & $(0,032)$ \\
\hline \multirow{2}{*}{ SGR } & $0,93^{* * *}$ & $0,97^{* * *}$ & $0,97^{* * *}$ & $0,79^{* * *}$ & $0,84^{* * *}$ \\
\hline & $(0,045)$ & $(0,044)$ & $(0,043)$ & $(0,045)$ & $(0,042)$ \\
\hline \multirow{2}{*}{ Capitales*Transf } & & $0,17^{* * *}$ & $0,12^{* * *}$ & $0,13^{* * *}$ & $0,08^{* * *}$ \\
\hline & & $(0,043)$ & $(0,038)$ & $(0,040)$ & $(0,035)$ \\
\hline \multirow{2}{*}{$100 \mathrm{Hab}^{*}$ Transf } & & $0,06^{* * *}$ & $0,06^{* * *}$ & $0,06^{* * *}$ & $0,03^{* * *}$ \\
\hline & & $(0,009)$ & $(0,009)$ & $(0,009)$ & $(0,008)$ \\
\hline \multirow{2}{*}{ Capitales*Reg } & & & $0,03^{* * *}$ & $0,03^{* * *}$ & $0,03^{* * *}$ \\
\hline & & & $(0,013)$ & $(0,013)$ & $(0,011)$ \\
\hline \multirow{2}{*}{ 100Hab*Reg } & & & 0,01 & 0,01 & 1,01 \\
\hline & & & $(0,014)$ & $(0,014)$ & $(0,013)$ \\
\hline \multirow{2}{*}{ Log(Otros_Imp) } & & & & $0,06^{* * *}$ & $0,06^{* * *}$ \\
\hline & & & & $(0,006)$ & $(0,006)$ \\
\hline \multirow{2}{*}{ Log(Población) } & & & & & $0,77^{* * *}$ \\
\hline & & & & & $(0,066)$ \\
\hline \multirow{2}{*}{ Constante } & $2,36^{* * *}$ & $2,46^{* * *}$ & $2,46^{* * *}$ & $2,34^{* * *}$ & $-4,79^{* * *}$ \\
\hline & $(0,114)$ & $(0,112)$ & $(0,111)$ & $(0,119)$ & $(0,641)$ \\
\hline \multirow{2}{*}{ Observaciones Número de Municipios } & 28.852 & 28.852 & 28.852 & 27.977 & 27.972 \\
\hline & 1.100 & 1.100 & 1.100 & 1.100 & 1.100 \\
\hline \multirow{2}{*}{ R-Cuadrado Rho } & 0,50 & 0,50 & 0,50 & 0,51 & 0,52 \\
\hline & 0,86 & 0.84 & 0.85 & 0,83 & 0,79 \\
\hline
\end{tabular}

Nota: Rho representa la fracción de la varianza explicada por $u_{i} \cdot{ }^{*}, * * * * *$ indican niveles de significancia del $10 \%, 5 \%$ y $1 \%$, respectivamente. Errores estándar robustos en paréntesis.

Fuente: cálculos de los autores con datos del DNP. 
Con respecto a las reformas a los sistemas de transferencias y regalías, todas estas generaron un cambio estructural positivo en el recaudo de impuesto predial. Tomando como punto de comparación el período 1984-1992, el recaudo por impuesto predial aumentó en un $45 \%, 72 \%$ y $84 \%$ con las reformas de situado fiscal y participaciones municipales, SGP y SGR, respectivamente - modelo (5)-.

Los coeficientes asociados a las interacciones de transferencias y regalías con categorías de municipios también van en línea con lo esperado. Las capitales, seguidas de los municipios con más de 100 mil habitantes, presentan aumentos mayores en el predial que el resto de municipios. En particular, ante el aumento en las transferencias, las capitales y municipios con más de 100 mil habitantes lograron un recaudo del predial del $0,08 \%$ y $0,03 \%$ superior al de los municipios en categoría 'resto', respectivamente.

Los efectos presentados se mantienen al reemplazar las categorías de municipios consideradas (capitales, mayor a 100 mil habitantes y resto) por el concepto de entornos de desarrollo definido por el DNP. Este último clasifica a los municipios en tres tipologías (desarrollo temprano, desarrollo intermedio y desarrollo robusto), de acuerdo con su dinámica económica, calidad de vida, medio ambiente, seguridad, desempeño institucional y funcionalidad urbano-regional (DNP, 2015). El anexo 4 presenta los resultados obtenidos al considerar esta categorización.

Una vez más, se descarta la existencia de pereza fiscal por parte de los municipios en el período analizado. Los aumentos en transferencias y regalías han estado asociados con cambios positivos en el recaudo del predial. Adicionalmente, con la metodología aplicada en esta sección, se encuentran cambios estructurales positivos durante todas las reformas en cuestión, así como efectos diferenciales entre categorías de municipios, siendo las capitales las de mayor aporte al crecimiento del recaudo.

\subsection{Discusión}

Diversos argumentos de carácter institucional y de coyuntura económica son importantes a la hora de explicar los resultados obtenidos. En materia de instituciones, el establecimiento de nuevas reglas relacionadas con la sostenibilidad de la deuda pública ha incentivado el crecimiento de los ingresos propios en las entidades territoriales. La Ley 550 de 1999, por ejemplo, contempla dentro de sus medidas de saneamiento de pasivos el aumento de la capacidad recaudatoria en municipios y departamentos. Según el мнср (2014), el crecimiento promedio del esfuerzo fiscal en los municipios que suscribieron acuerdos de pasivos fue superior en un $6,9 \%$ al de las entidades que 
no suscribieron dicho acuerdo. Coherente con este resultado, Palencia (2017) encuentra que esta misma ley ha afectado positivamente el recaudo tributario de los municipios en la costa Caribe. Es importante aclarar que, en algunos casos, no persisten los efectos en los ingresos luego de terminado el acuerdo. En relación con esto, la CGR (2008) reporta resultados fiscales negativos en las entidades territoriales que culminaron exitosamente el acuerdo. Existe, además, un conjunto de leyes que ha impuesto límites al nivel de deuda y gastos de los gobiernos subnacionales (Ley 358 de 1997; Ley 617 de 2000; Ley 819 de 2003), promoviendo así la sostenibilidad de la deuda pública territorial e incentivando de igual forma el aumento de los ingresos.

Otro aspecto institucional relacionado con el aumento de los ingresos tributarios es el crecimiento de las bases tributarias. Durante los últimos años, las administraciones locales han realizado esfuerzos en materia de actualizaciones catastrales, los cuales han sido diferenciales entre regiones y entre zonas rurales y urbanas. Bogotá es un ejemplo de enorme esfuerzo, con un valor total de avalúos que pasó de \$59,6 billones en el año 2000 a \$365,2 billones en 2015 (Lozano y Ricciulli, 2017). A nivel nacional, según el IGAC (2010), entre 2002 y 2010, el avalúo de la base catastral aumentó un 154,2 \% y el número de predios inscritos se incrementó en un 20,7\%.

Con respecto al tema, Zapata (2010) menciona el régimen especial del Distrito Capital (Ley 1421 de 1993) como uno de los impulsores del crecimiento de los ingresos municipales. Además de incrementar los ingresos de la capital del país, el autor señala que este sirvió de base para que otros municipios adoptaran nuevos cobros, modernizando sus catastros, poniendo en marcha el autoavalúo o extendiendo el cobro del ICA a otras actividades. Por otro lado, este mismo autor subraya la relevancia de algunas reformas tributarias nacionales que incluyeron artículos que favorecen los fiscos de los GSN, como, por ejemplo, la creación de la sobretasa a la gasolina con la Ley 86 de 1989 y las importantes consideraciones sobre los impuestos al consumo de licores, vinos y aperitivos incluidas en la Ley 788 de 2002. De igual manera, vale la pena mencionar que, por ejemplo, en algunos planes de desarrollo nacional se incluyeron incrementos a las tarifas máximas que los municipios podrían aplicar en el impuesto predial.

Por último, y no menos importante, la coyuntura económica en los períodos analizados ha influido en el comportamiento de los ingresos tributarios. De manera especial, el auge del sector minero-energético en el período 2002-2012 contribuyó al aumento observado en el recaudo del IcA. En este período, la correlación entre el PIB y el recaudo del ICA es significativamente alta, indicando una importante dependencia del recaudo tributario a la coyuntura económica del período. 


\section{Conclusiones y recomendaciones de política}

La profundización de la descentralización en Colombia a partir de la Constitución Política de 1991 llevó a que las trasferencias desde el gobierno nacional a los municipios y departamentos se incrementaran. El aumento significativo en recursos implicó una menor autonomía local, a pesar de que se observó una mayor generación de recursos propios. Los resultados no permiten concluir que las transferencias generen una pereza fiscal en Colombia, ya que las mayores transferencias no implicaron una menor recolección de recursos propios en los GSN. Las dos fuentes crecieron durante el período, aunque las transferencias lo hicieron a un mayor ritmo que los recursos propios.

Esta conclusión general tiene ciertas diferencias cuando se analizan los distintos tributos de los GSN, las reformas en los sistemas de transferencias y el tipo y tamaño de los GSN. Se observa, por ejemplo, que el impuesto predial es menos dinámico que el impuesto de industria y comercio. Es probable que el dinamismo de este último esté asociado con un mejor desempeño de la actividad económica en ciertos territorios, por ejemplo, por una mayor explotación minera dentro de sus fronteras. En cuanto a los distintos sistemas estudiados, se encuentra un mayor esfuerzo recaudatorio en las reformas que aumentaron las transferencias que en aquellas donde se incrementaron las regalías. Finalmente, las reformas que se dieron en el tiempo exhiben comportamientos heterogéneos de acuerdo con el tamaño de las municipalidades. Para el caso del aumento en transferencias, las capitales, seguidas de los municipios con más de 100 mil habitantes, presentaron un mayor esfuerzo fiscal que el resto de municipios.

Si bien los resultados no parecen mostrar indicios de pereza fiscal por parte de las entidades territoriales, la alta dependencia de las transferencias es sin duda un factor de riesgo que debe considerarse. Aunque no existe una fórmula única a través de la cual se puede reducir el riesgo de enfrentar pereza fiscal, sí existen algunas acciones que bien implementadas pueden llevar a fortalecer los ingresos propios de los gobiernos subnacionales. Dentro de las posibles estrategias existe un primer grupo que depende directamente de la voluntad y los buenos oficios de los gobiernos subnacionales. Las dos primeras, y que deberían implementarse casi simultáneamente, son la modernización de los sistemas de cobro, a través de la facturación electrónica, y el fortalecimiento del recurso humano a cargo de los equipos de trabajo de hacienda y planeación. Estos cambios son una condición necesaria previa a cualquier otra acción, y que incluso generan resultados positivos inmediatos en los ingresos propios de municipios y departamentos. Una tercera acción es la simplificación del marco legal, mediante estatutos tributarios territoriales 
modernos que faciliten a la entidad y los usuarios el proceso del pago de impuestos. Finalmente, pero no menos importante es la actualización de las bases tributarias, principalmente del impuesto de industria y comercio y del predial. Para este último existe una oportunidad única para los predios rurales por medio del reciente Censo Agropecuario.

El segundo conjunto corresponde a todas aquellas acciones por medio de las cuales los gobiernos subnacionales se pueden beneficiar a través del ahorro y reducción del gasto y, por ende, del aumento en sus ingresos propios de libre destinación. Todas ellas buscan hacer más democráticos y transparentes los procesos de contratación. Por ejemplo, la estandarización de los procedimientos mediante pliegos únicos en toda la contratación pública, homologando los términos de referencia para contratar obras similares ejecutadas en distintos municipios del país. La segunda es la implementación generalizada y obligatoria, para todo el sector público, de agencias de compras, las cuales facilitan la planificación, organización y ejecución de las compras del sector público, nacional y territorial. Relacionadas con las anteriores están las subastas electrónicas y la libertad de proponentes, que buscan facilitar la dinámica entre compradores y proveedores, reduciendo los costos administrativos y transaccionales.

Se podría pensar que estas estrategias podrían ser altamente costosas y que los municipios y departamentos tendrían que hacer grandes inversiones en su implementación. Sin embargo, como se vio anteriormente, para algunas de ellas solo basta tener la voluntad de hacerlo. En otros casos, las entidades territoriales deberán hacer algunas inversiones e incurrir en algunos gastos que, contrario a otros del sector público, se reflejarán en mayores ingresos de libre destinación. Dentro de las posibles fuentes de recursos para la implementación de estas acciones están las transferencias no condicionadas, especialmente regalías, así como los recursos propios de cada entidad territorial. Cualquier inversión bien ejecutada en desarrollo tecnológico y el fortalecimiento del equipo técnico de cualquier entidad del Estado resultarán en mayor eficiencia y mayores recursos para ser invertidos en mejorar la calidad de vida de sus habitantes.

\section{Referencias}

Alesina, A. (2002). Institutional reforms in Colombia. Documento de Trabajo $N^{o}$ 21. Bogotá: Fedesarrollo.

BID. (2012). Más ingresos propios para más desarrollo local. En A. Corbacho, V. Fretes \& E. Lora (Eds.), Recaudar no basta. Washington D.C.: Banco Interamericano de Desarrollo (BID). 
Bonet, J., \& Ayala, J. (2016). La brecha fiscal territorial en Colombia. Documentos de Trabajo sobre Economía Regional N² 235. Cartagena: Banco de la República.

Bonet, J., \& Pérez, G. (septiembre-diciembre, 2016). Cambios recientes y perspectivas del Sistema General de Participaciones. Economía Colombiana, 347, 50-61.

Bonet, J., \& Urrego, J. (2014). El Sistema General de Regalías: ¿mejoró, empeoró o quedó igual? Documentos de Trabajo sobre Economía Regional No 198. Cartagena: Banco de la República.

Bonet, J., Pérez, G. J., \& Ayala, J. (2014). Contexto histórico y evolución del sGP en Colombia. En J. Bonet \& L. A. Galvis (Eds.), Sistemas de transferencias subnacionales: lecciones para una reforma en Colombia. Bogotá: Banco de la República.

Cadena, X. (septiembre, 2002). ¿La descentralización empereza? Efecto de las transferencias sobre los ingresos tributarios municipales en Colombia. Desarrollo y Sociedad, (50), 67-108.

Contraloría General de la República. (2008). Política de saneamiento fiscal y financiero de los entes territoriales. Bogotá: CGR.

Contraloría General de la República. (2015). Resultados del Sistema General de Regalías a diciembre de 2015. Bogotá: CGR.

Departamento Nacional de Planeación. (2015). Tipologías departamentales y municipales: una propuesta para comprender las entidades territoriales colombianas. Bogotá: DNP.

Fainboim, I., Olivera, M., \& Alonso, J. C. (septiembre, 1997). La sostenibilidad de la política fiscal colombiana. Coyuntura Económica, 27(3), 101-118.

Hernández, A., \& Herrera, F. (2015). Evaluación del Sistema General de Regalías. Cuadernos PNud. Bogotá: Programa de las Naciones Unidas para el Desarrollo.

Instituto Geográfico Agustín Codazzi. (2010). Informe de gestión 2002-2010. Bogotá: IGAC.

Junguito, R., Melo, L., \& Misas, M. (1995). La descentralización fiscal y la política macroeconómica. Borradores de Economía No 31. Bogotá: Banco de la República.

Lozano, I. (2001). Colombia's public finance in the 1990s: a decade of reforms, fiscal imbalance, and debt. Borradores de Economía N ${ }^{\circ} 174$. Bogotá: Banco de la República.

Lozano, I., \& Ricciulli, D. (2017). ¿Está afectando el impuesto predial el precio de la vivienda en Bogotá? Un análisis basado en la econometría espacial. Borradores de Economía No 1016. Bogotá: Banco de la República. 
Martínez, L. (2017). Sources of revenue and government performance: evidence from Colombia. Working Paper. University of Chicago.

Melo, L. (2001). The flypaper effect under different institutional contexts: the Colombian case. Public Choice, 111(3), 317-245.

Ministerio de Hacienda y Crédito Público. (2006). Exposición de motivos Acto Legislativo 4 de 2007. Gaceta del Congreso, (366).

Ministerio de Hacienda y Crédito Público. (2014). Efectos de la Ley de Reestructuración de Pasivos (Ley 550 de 1999) en las entidades territoriales. Bogotá: Dirección General de Apoyo Fiscal-мнсP.

Ministerio de Hacienda y Crédito Público. (2015). Responsabilidad fiscal subnacional y descentralización en Colombia: quince años de consolidación. Bogotá: MHCP.

Ministerio de Hacienda y Crédito Público. (2017). Boletín de Prensa, (79).

Palencia, M. A. (2017). Indicadores financieros en municipios de la costa Atlántica, antes, durante y después de haberse acogido a la Ley 550 de 1999 (Tesis de Maestría en Finanzas Corporativas, Colegio de Estudios Superiores de Administración - CESA-, Bogotá, Colombia).

Perry, G., \& Olivera, M. (2009). El impacto del petróleo y la minería en el desarrollo regional y local en Colombia. Documentos de Trabajo N 51 . Bogotá: Fedesarrollo.

Pessino, C., \& Fenochietto, R. (diciembre, 2010). Determining contries' tax effort. Hacienda Pública Española/Revista de Economía Pública, 195(4), 65-87.

Porto, A., Pineda, C., \& Eguino, H. (2017). Panorama de la descentralización y autonomía fiscal subnacional en América Latina. Documento de Trabajo. Washington D.C.: Banco Interamericano de Desarrollo (BID).

Ramírez, J. M., \& Bedoya, J. G. (2014). Regalías directas por hidrocarburos y esfuerzo fiscal municipal en Colombia. Coyuntura Económica, 44(2), 15-34.

Sánchez, J., Gutiérrez, C., \& Parra, J. C. (1994). Transferencias intergubernamentales y comportamiento fiscal. Coyuntura Económica, 24(2), 89-110.

Zapata, J. G. (2010). Las finanzas territoriales en Colombia. Documento de Trabajo. Bogotá: Fedesarrollo.

Zapata, J. G. (2016). Finanzas municipales en Colombia: buen desempeño pero se mantienen las desigualdades. Documento de Trabajo. Bogotá: Fedesarrollo.

Zapata, J. G., Acosta, O. L., \& Gonzáles, A. (2001). Evaluación de la descentralización municipal en Colombia. ¿Se consolidó la sostenibilidad fiscal de los municipios colombianos durante los años noventa? Archivos de Economía No 165. Bogotá: Departamento Nacional de Planeación. 


\section{Anexo 1. Definiciones de los indicadores fiscales}

\begin{tabular}{lc}
\hline & Indicadores de ahorro \\
\hline Ahorro primario & Ingreso corriente - Gastos funciona. - Otros gastos \\
Ahorro operacional & Ahorro primario - Intereses \\
Capacidad de ahorro & $\frac{\text { Ahorro operacional }}{\text { Ingreso corriente }}$ \\
Ahorro total & Ingreso total - Gastos funciona. - Intereses - Otros gastos \\
\hline & Indicadores de ingreso \\
\hline $\begin{array}{l}\text { Capacidad de generación ingresos } \\
\text { permanentes }\end{array}$ & $\underline{\text { Ingreso corriente }}$ \\
Importancia industria y comercio & Ingresos totales \\
Importancia del impuesto predial de industria y comercio & Ingreso corriente \\
Dependencia de las transferencias & $\underline{\text { Impuesto predial }}$ \\
Importancia de los ingresos de & Ingreso corriente \\
capital & Transferencias \\
\hline
\end{tabular}

Indicadores de gasto

$\%$ gastos funciona. en total gasto

Gastos de funcionamiento Gastos totales

$\%$ gastos de personal en gastos funciona.

Gastos personal

Capacidad financiación gastos funciona. Gastos funcionamiento

Gastos funcionamiento Ingresos corrientes

\% inversión en total del gasto

Gastos de inversión Gastos totales

Autofinanciación de la inversión

(Ahorro total - Transferencias nacionales) Gastos de inversión

Inversión financiada transferencias

Transferencias nacionales inversión

$\%$ intereses deuda en total gastos Intereses Gastos totales

Fuente: Zapata (2010). 


\section{Anexo 2}

A. Gobiernos municipales - indicadores fiscales, 1996-2015

A.1. Indicadores de ahorro
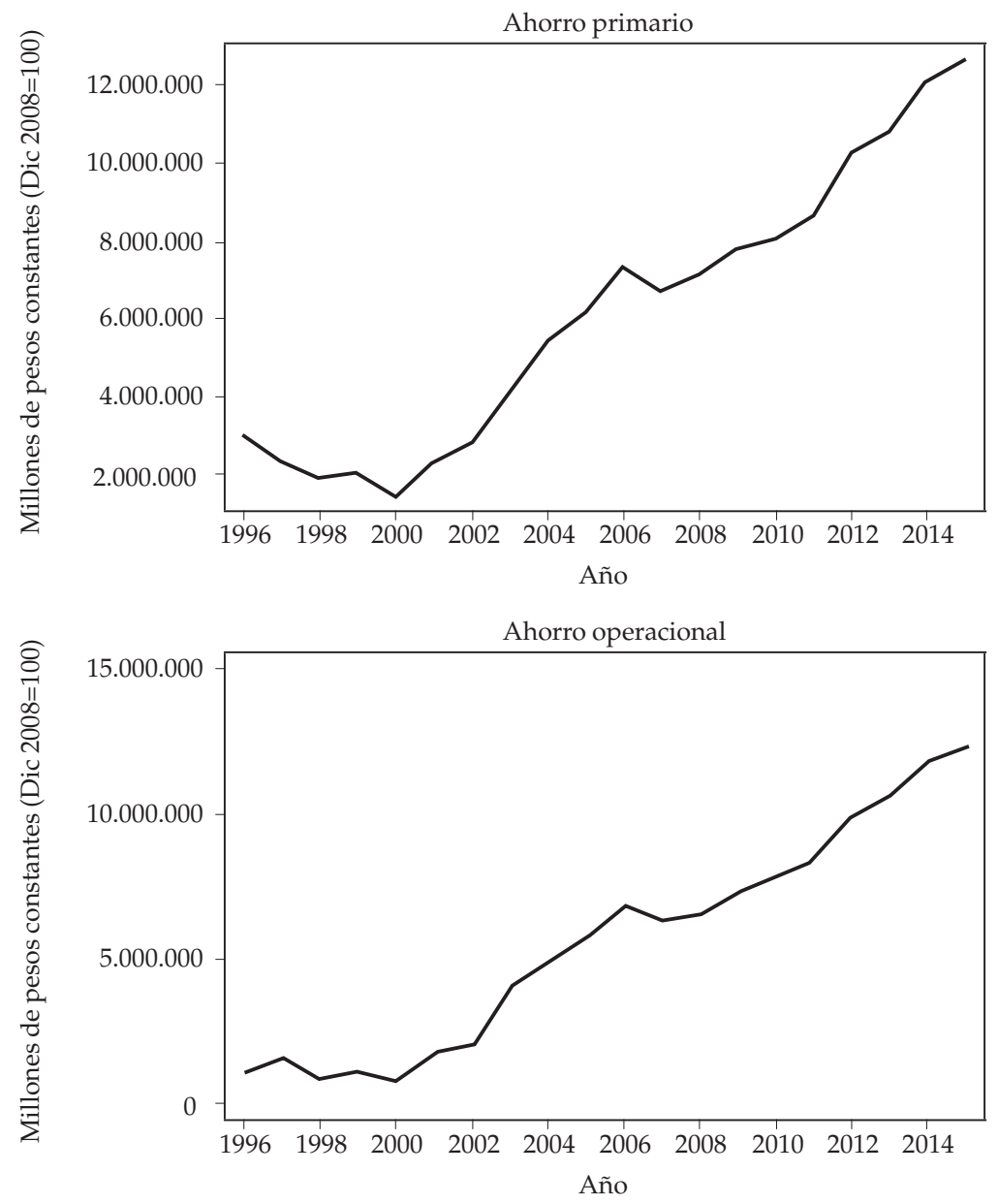

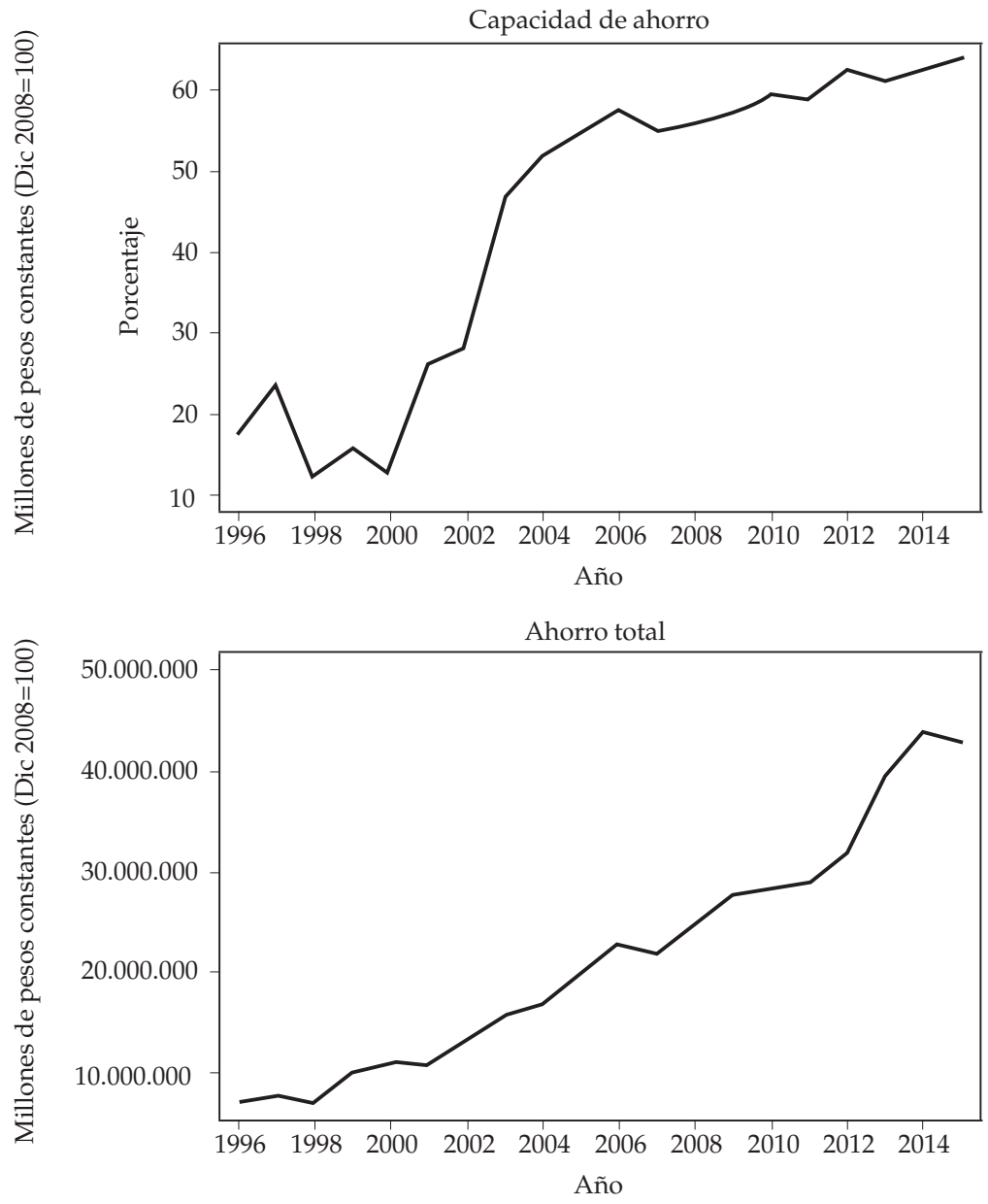


\section{A.2. Indicadores de ingreso}

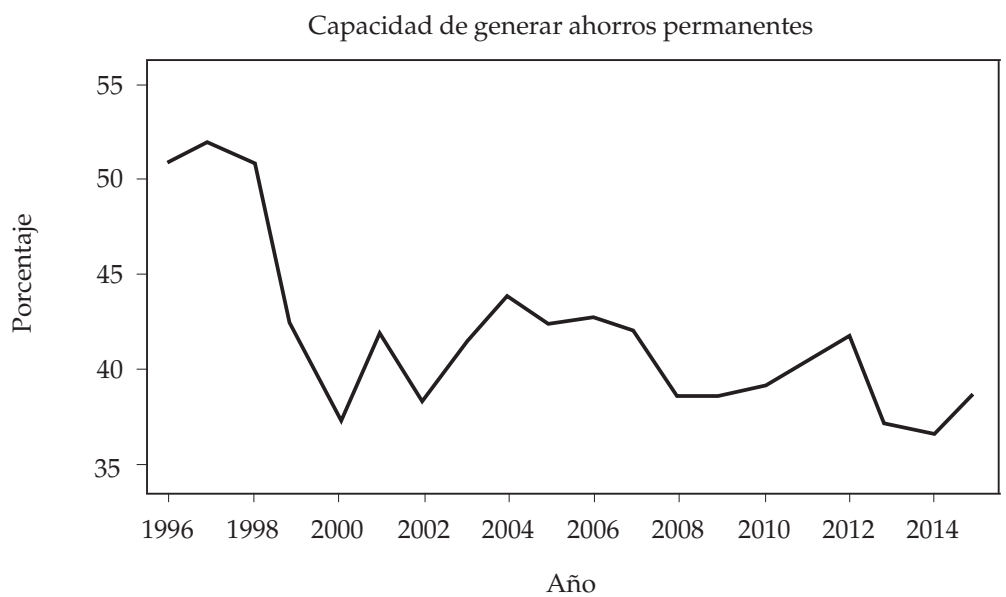

Importancia del ICA

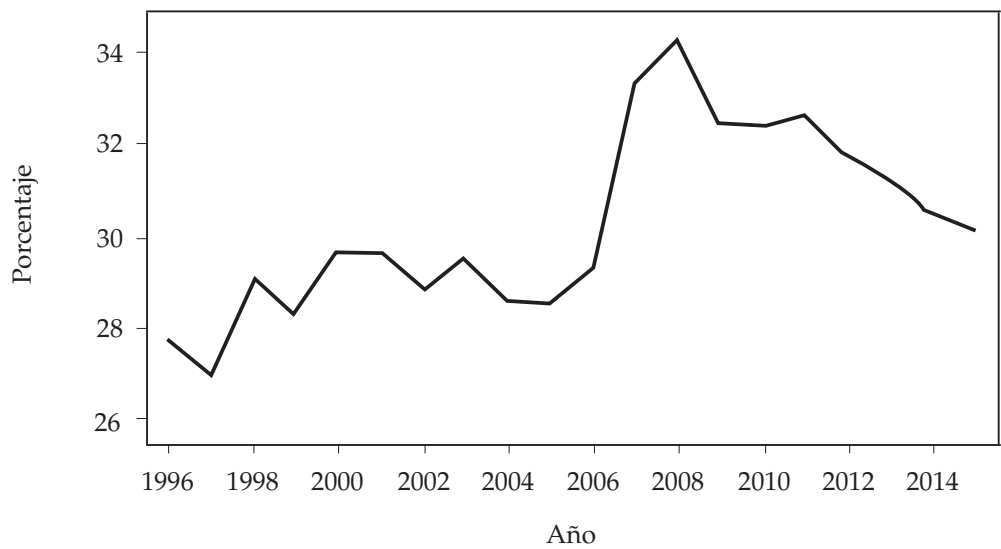

Importancia del predial

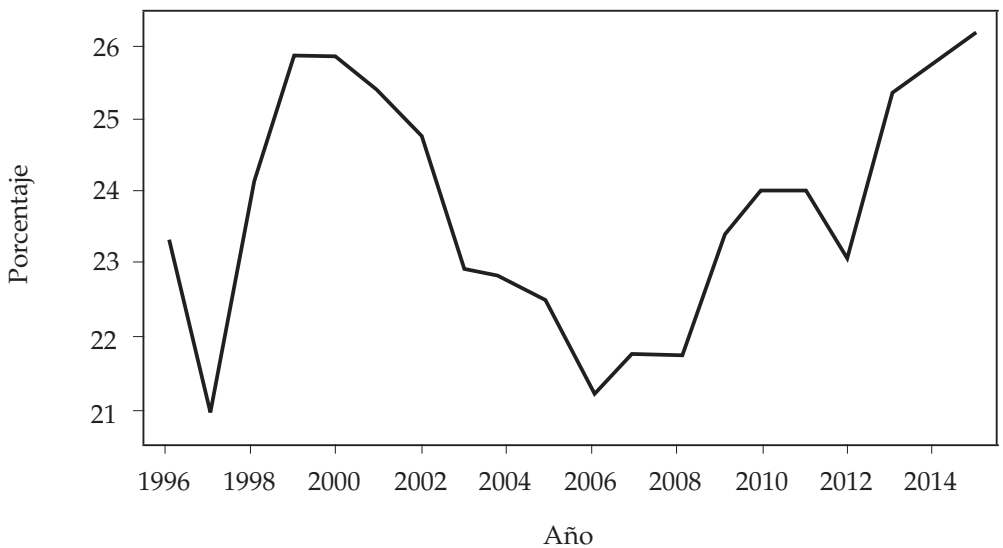



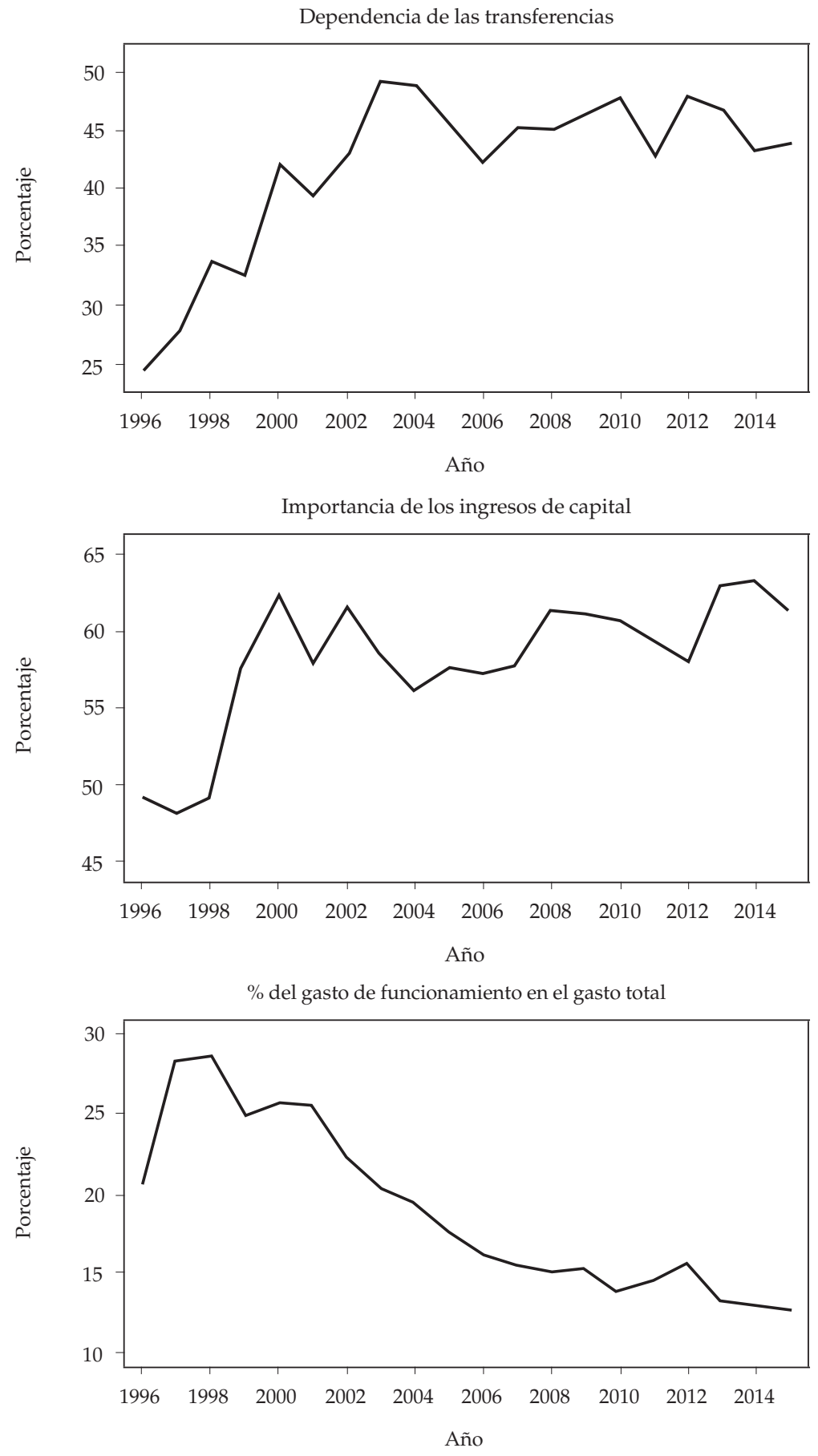


\section{A.3. Indicadores de gasto}
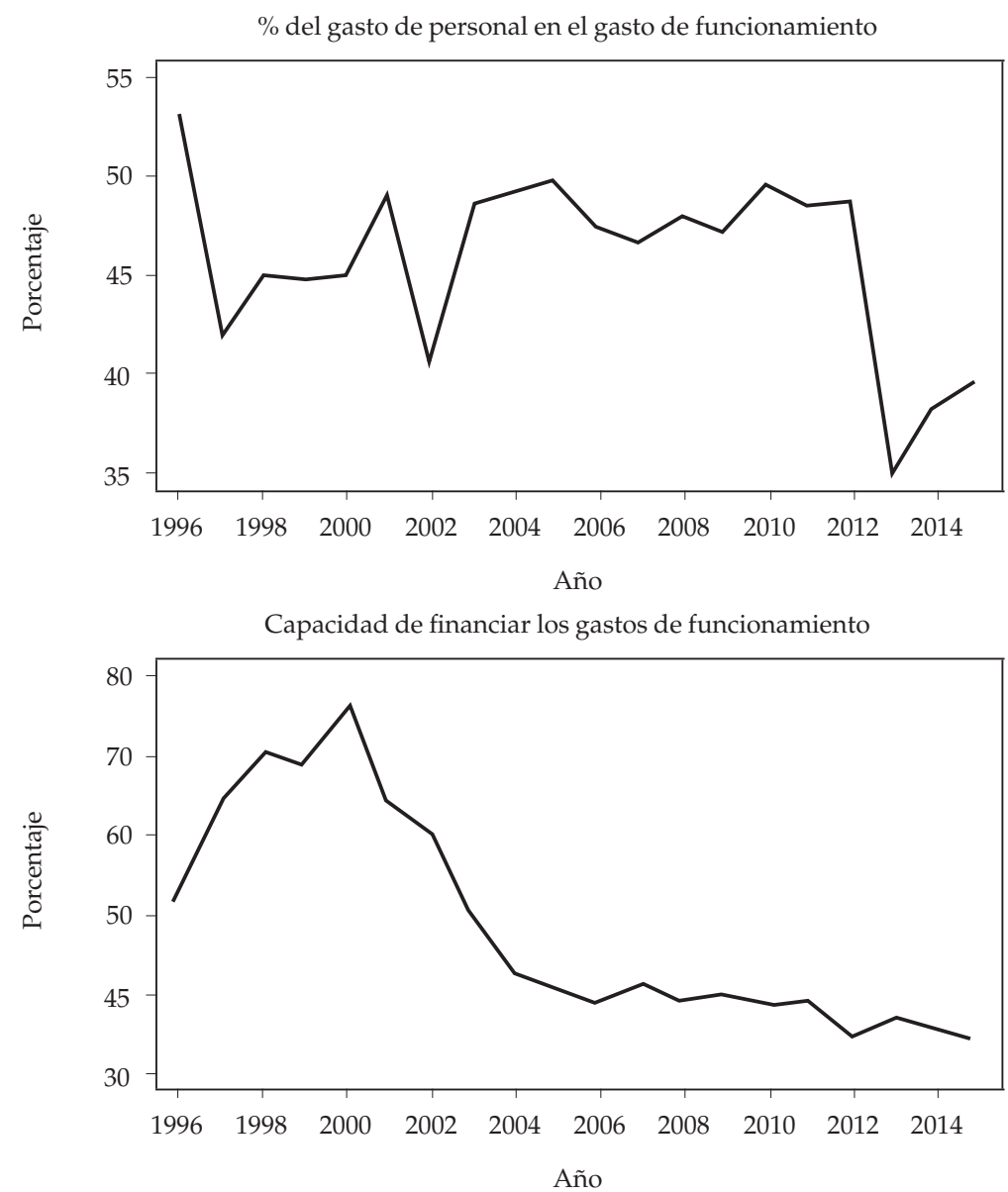

$\%$ de la invación en el gasto total

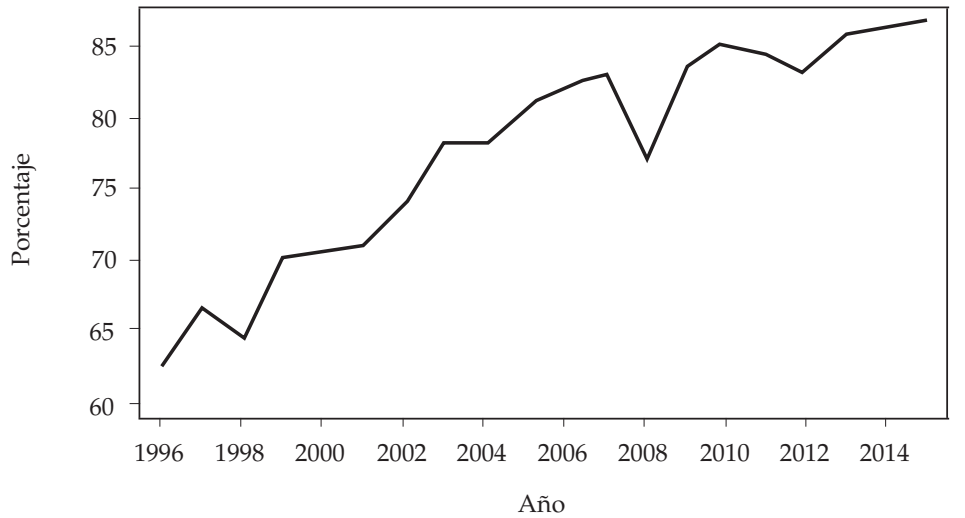



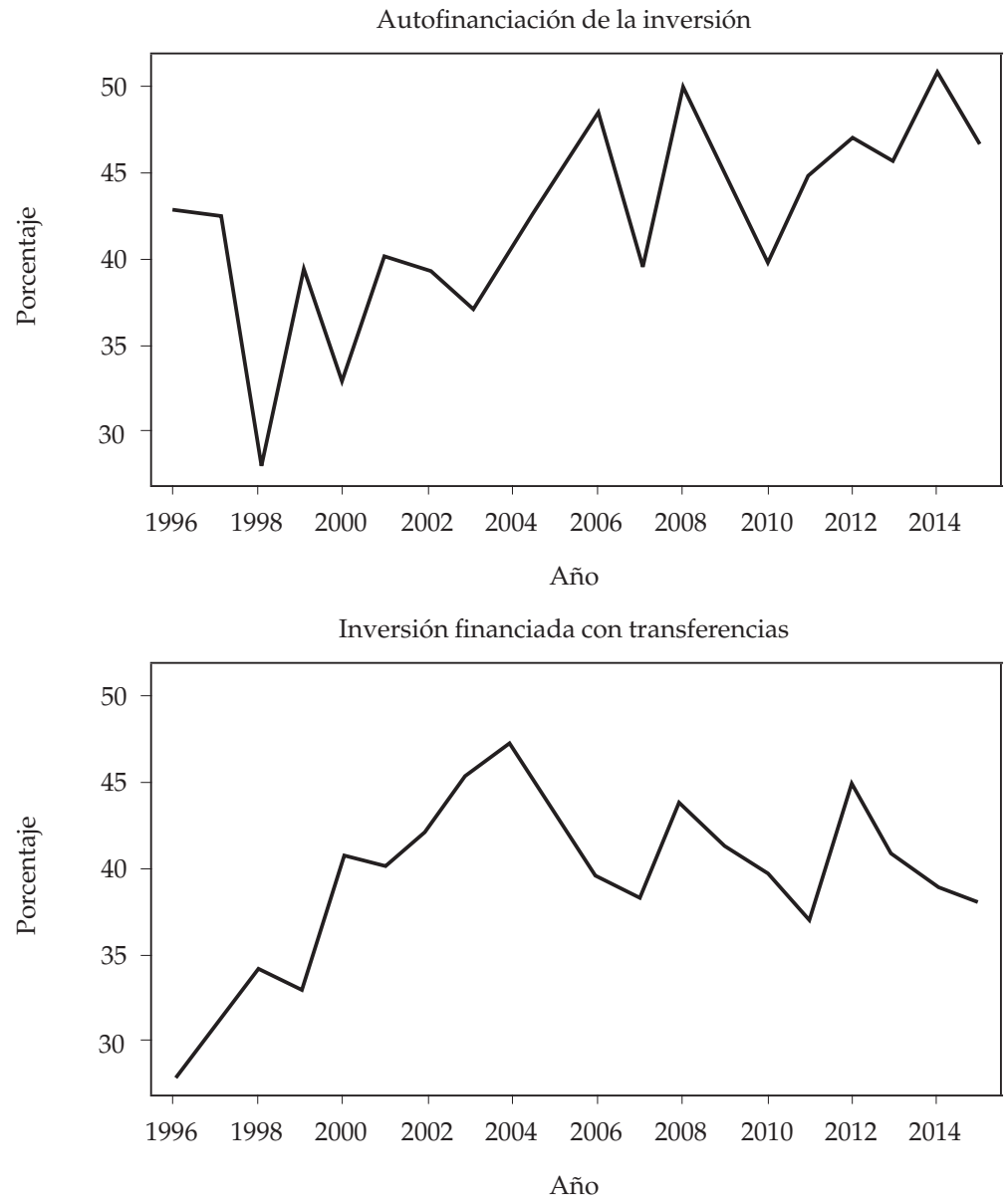

$\%$ de interés pagados por deuda pública en el gasto total

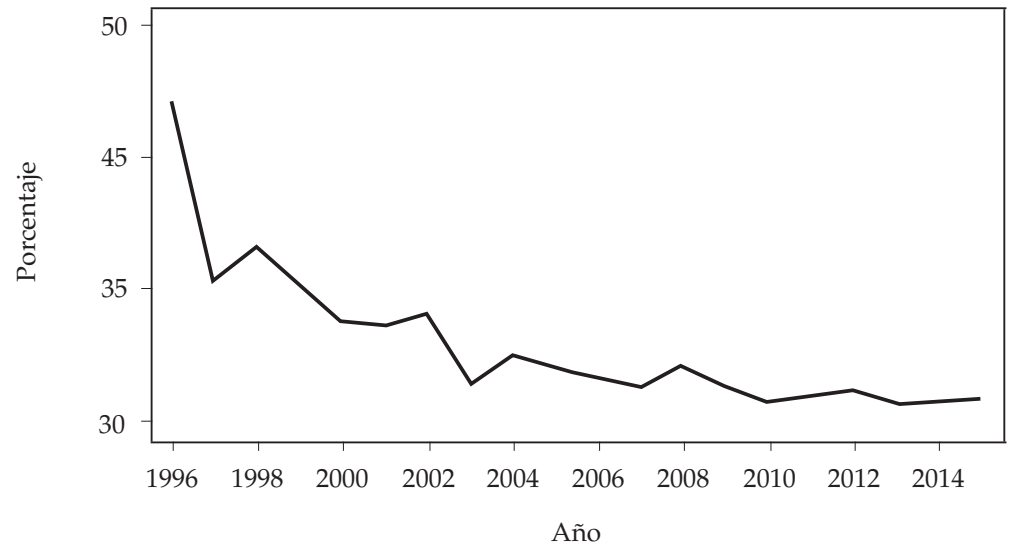

Fuente: DNP. Ejecuciones presupuestales. Cálculos de los autores. 
B. Gobiernos departamentales - indicadores fiscales, 1996-2015

B.1. Indicadores de ahorro
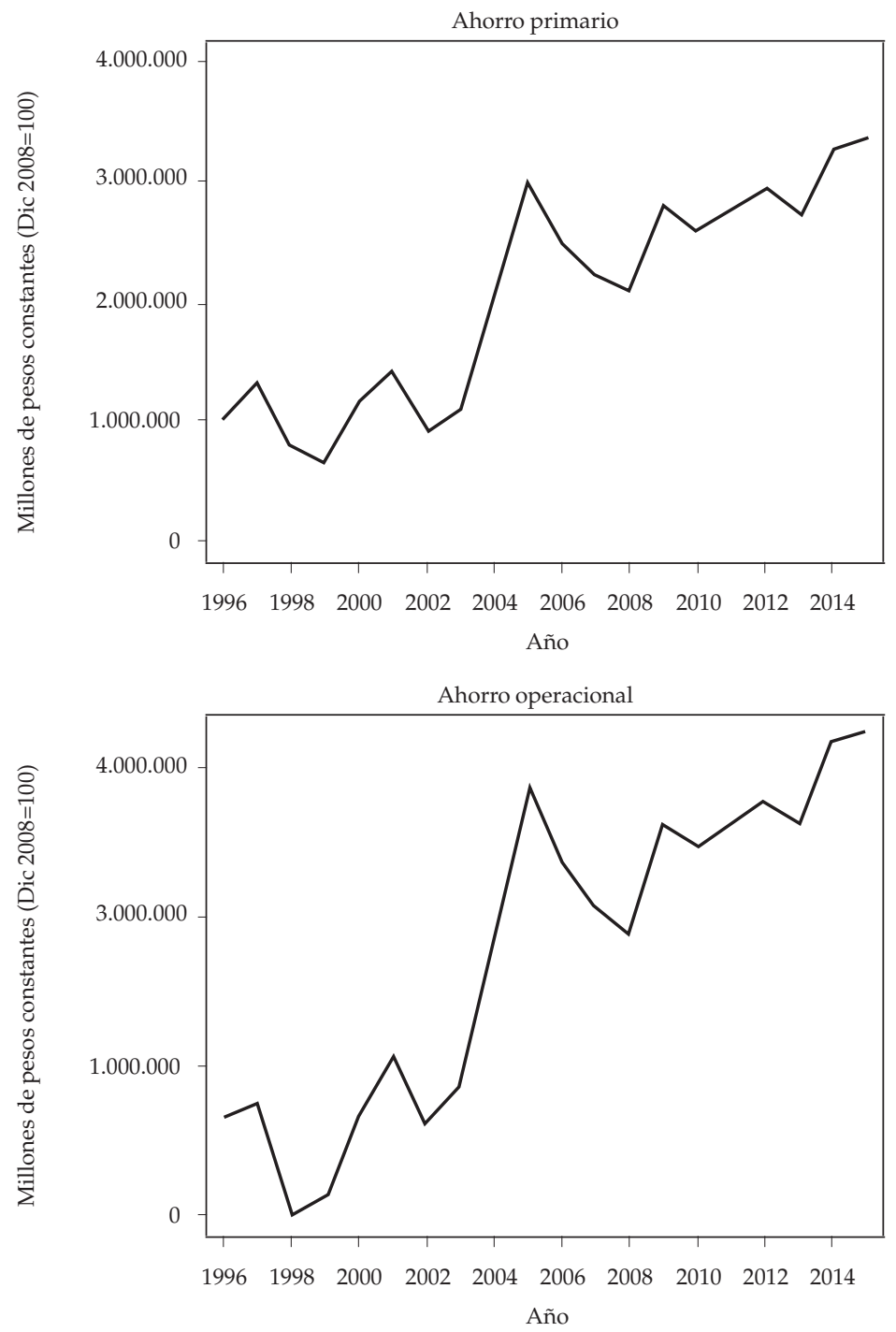

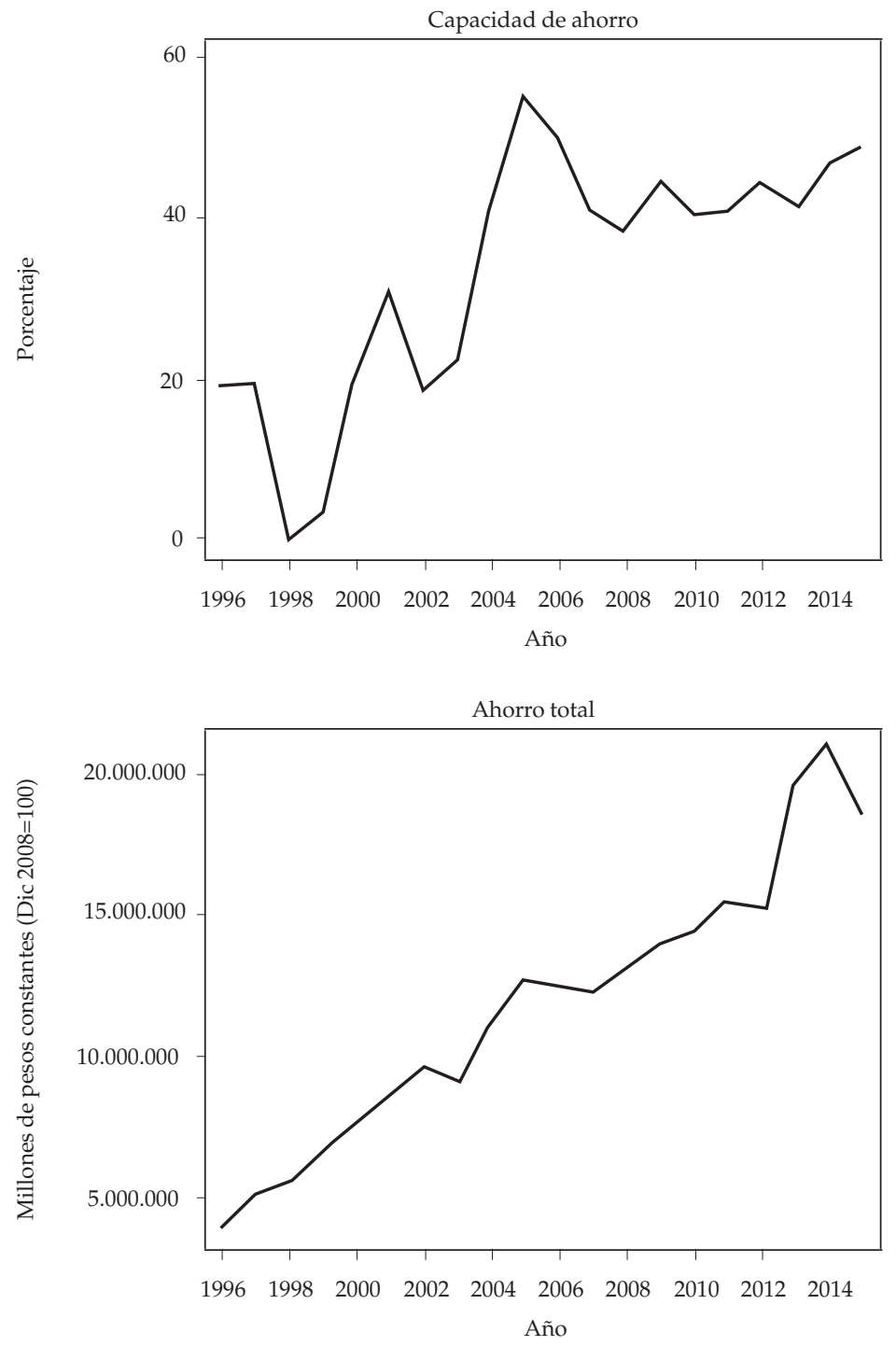


\section{B.2. Indicadores de ingreso}
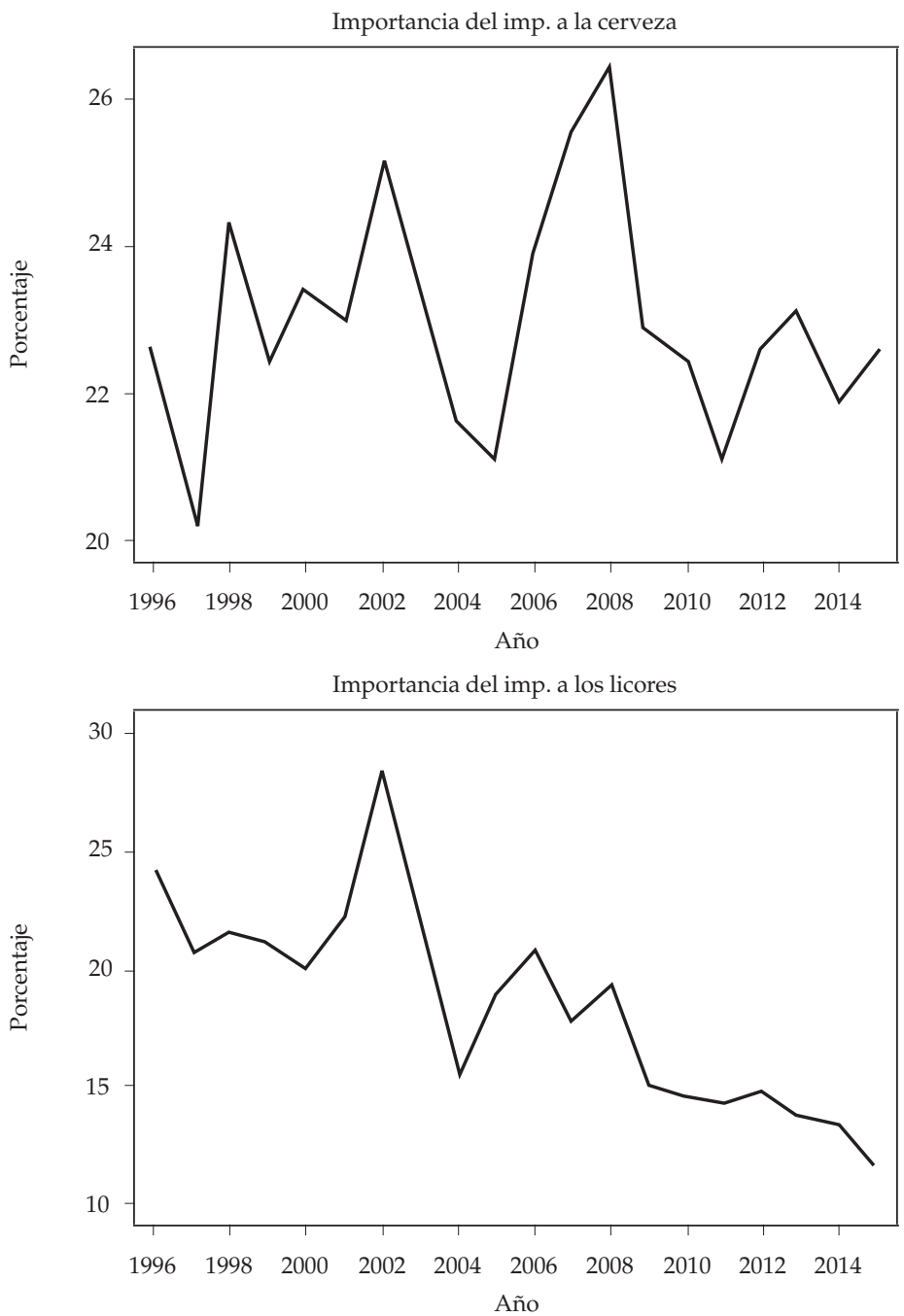

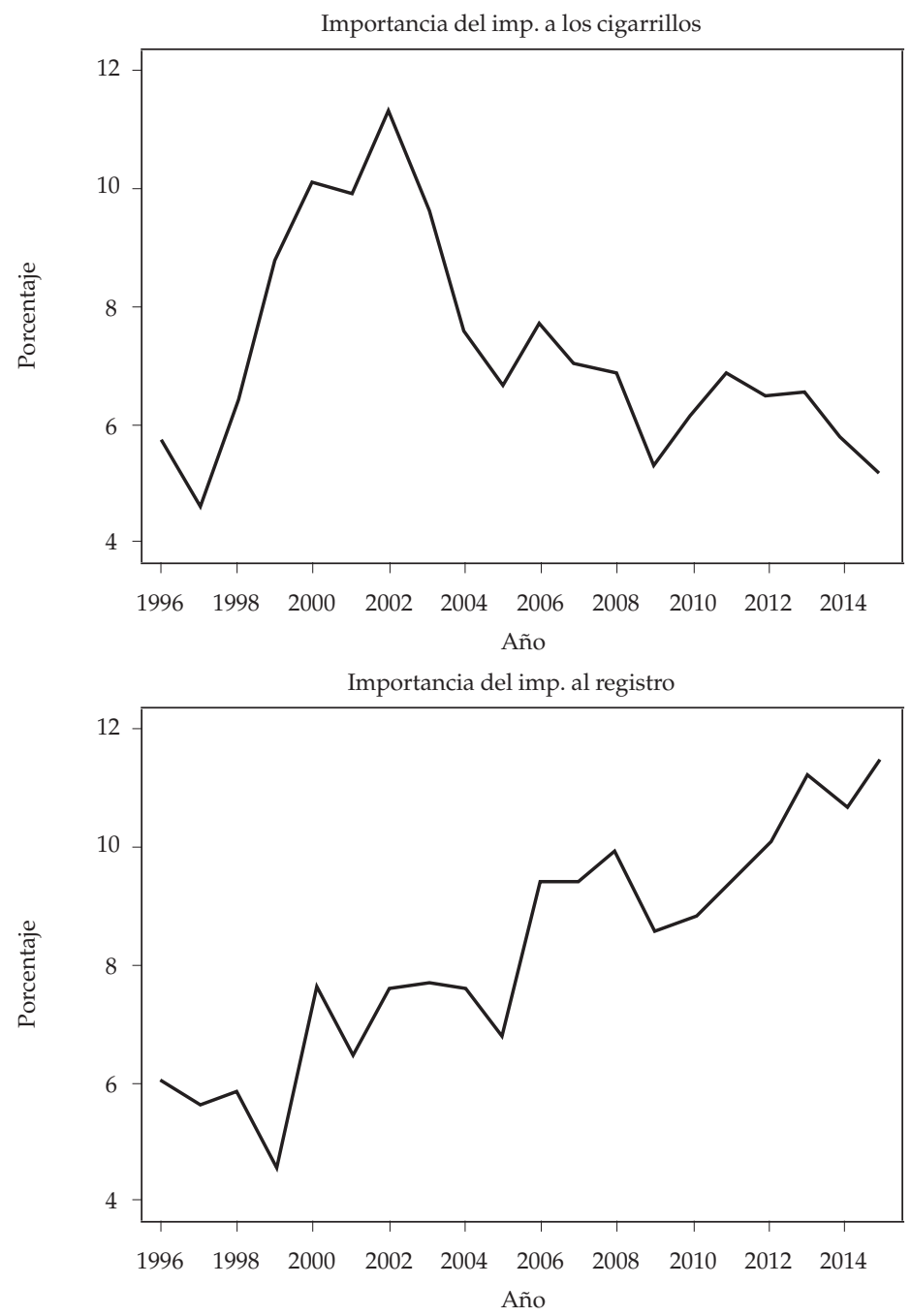

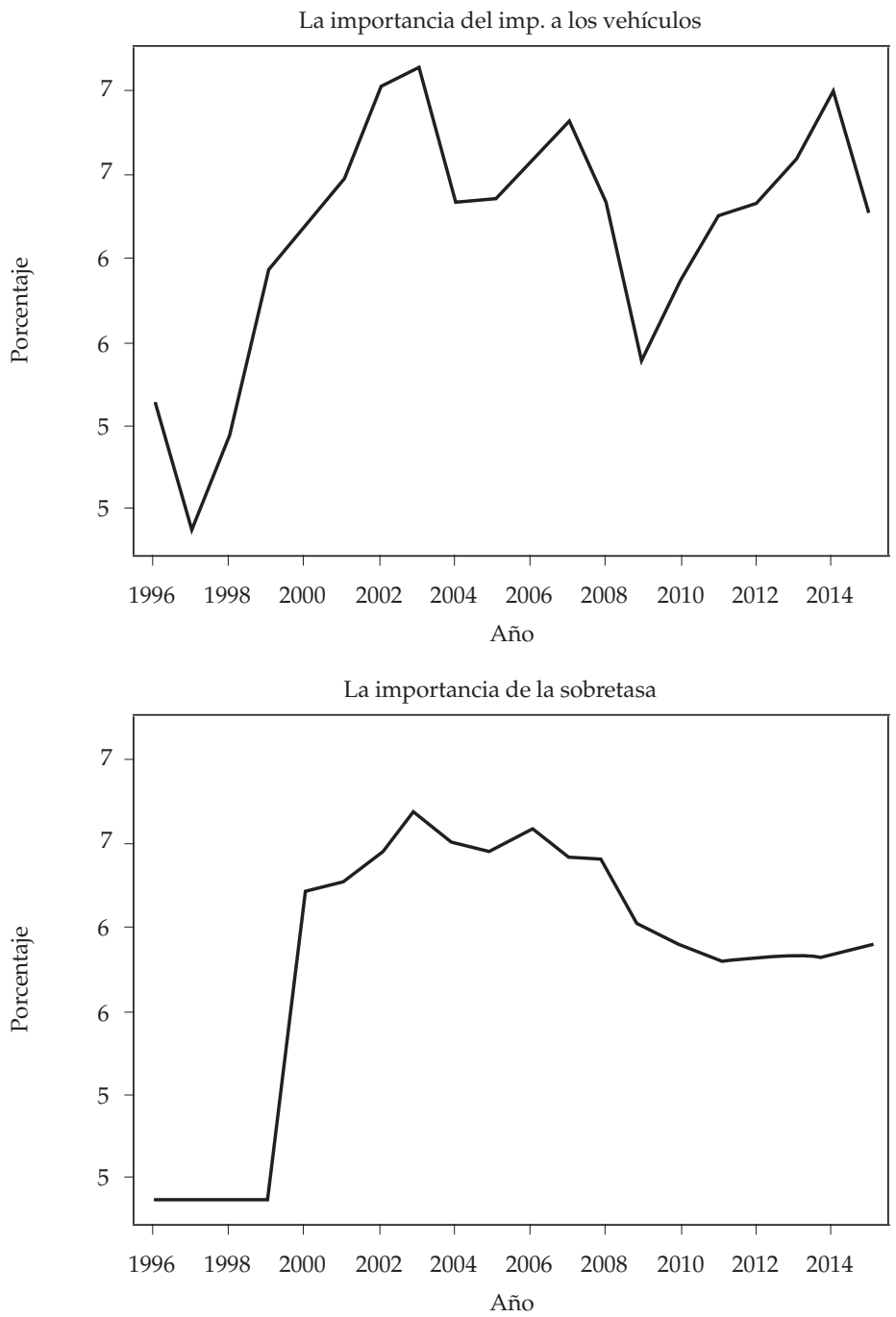


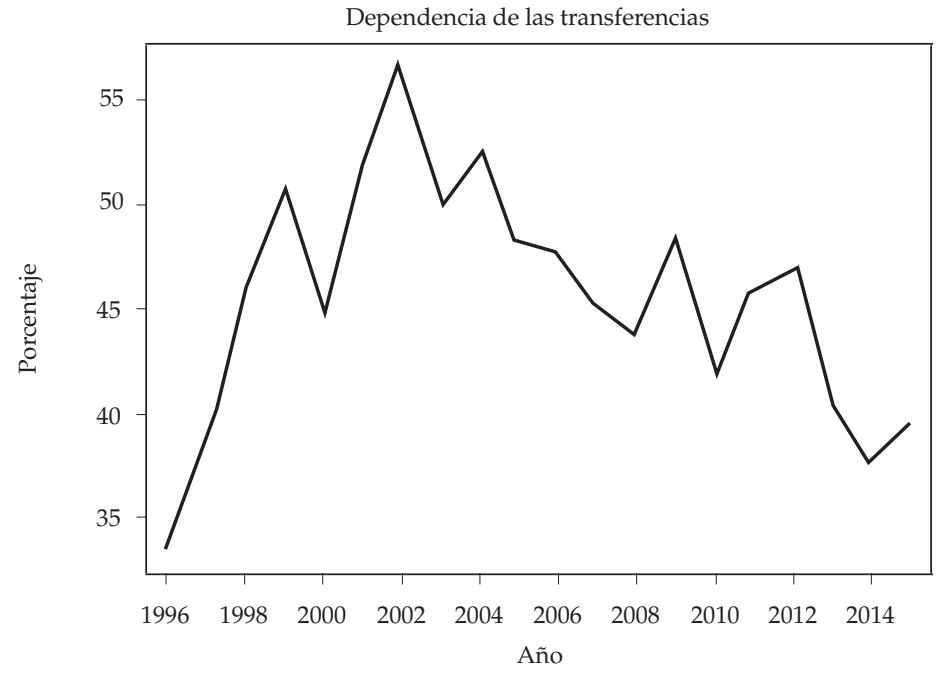

\section{B.3. Indicadores de gasto}
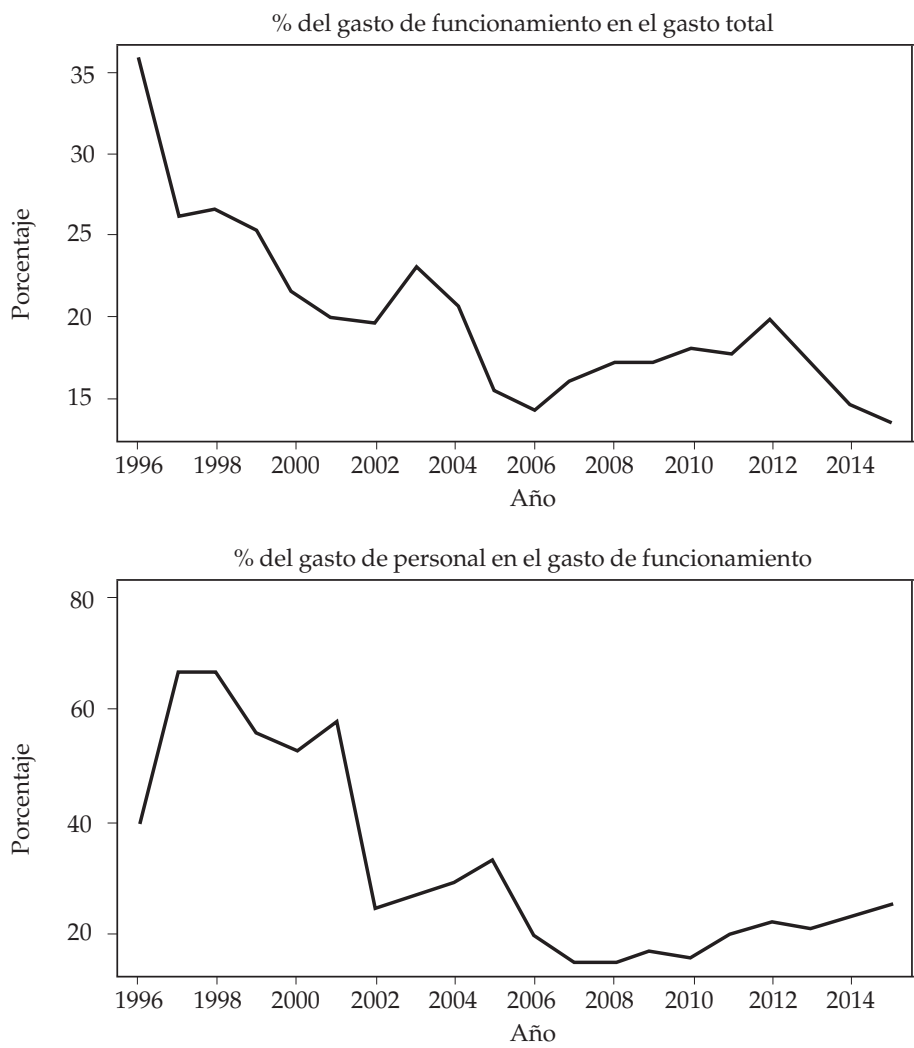

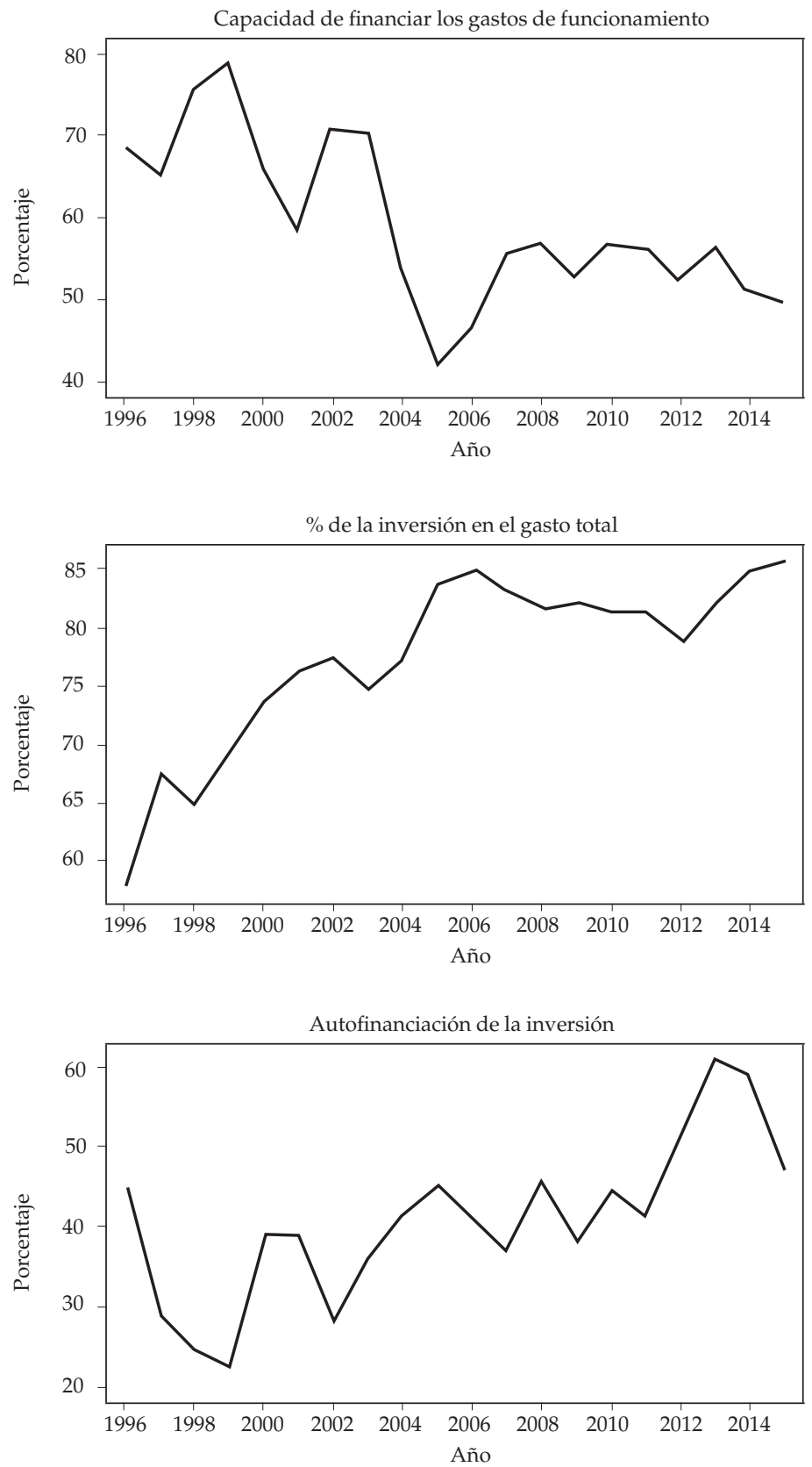

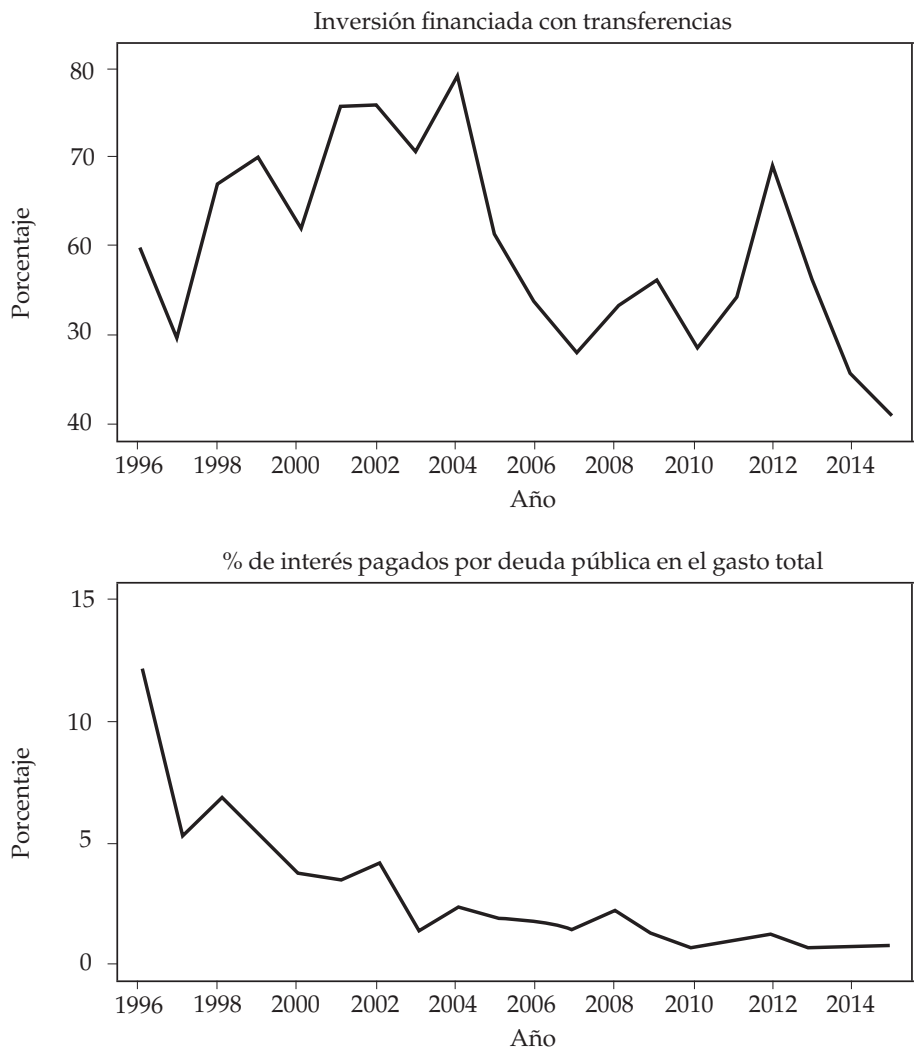

Fuente: DNP. Ejecuciones presupuestales. Cálculos de los autores. 


\section{Anexo 3. Crecimiento anual de transferencias e ingresos tributarios, promedio departamentos}

(Porcentajes)

\begin{tabular}{|c|c|c|}
\hline & Pre-Reforma & Post-Reforma \\
\hline \multicolumn{3}{|c|}{ Reforma 1: Situado Fiscal y part. municipales } \\
\hline & 1984-1992 & $1993-2000$ \\
\hline Transferencias & $-1,6$ & 71,7 \\
\hline Ingresos Tributarios & 1,9 & 5,6 \\
\hline \multicolumn{3}{|c|}{ Reforma 2: SGP } \\
\hline & 1994-2001 & 2002-2011 \\
\hline Transferencias & 70,9 & 18,4 \\
\hline Ingresos Tributarios & 4,9 & 7,6 \\
\hline \multicolumn{3}{|c|}{ Reforma 3: SGR } \\
\hline & 2003-2011 & 2012-2014 \\
\hline Regalías & 6,4 & 110,2 \\
\hline Ingresos Tributarios & 6,8 & 8 \\
\hline
\end{tabular}

Nota: Los crecimientos aquí definidos se calculan como proporción de los ingresos propios en el período inicial. Fuente: cálculos de los autores con datos del DNP.

\section{Anexo 4. Resultados modelo de efectos fijos con categorización de municipios DNP}

\begin{tabular}{cccccc}
\hline & \multicolumn{5}{c}{ Panel con efectos fijos } \\
\hline $\log ($ Predial $)$ & $(1)$ & $(2)$ & $(3)$ & $(4)$ & $(5)$ \\
\hline \multirow{2}{*}{$\log ($ Transf $)$} & $0,25^{* * *}$ & $0,19^{* * *}$ & $0,21^{* * *}$ & $0,20^{* * *}$ & $0,18^{* * *}$ \\
& $(0,017)$ & $(0,024)$ & $(0,025)$ & $(0,026)$ & $(0,024)$ \\
$\log ($ Reg $)$ & $0,02^{* * *}$ & $0,02^{* * *}$ & 0,00 & 0,00 & $-0,01$ \\
& $(0,003)$ & $(0,003)$ & $(0,006)$ & $(0,006)$ & $(0,006)$ \\
SituadoYParticip & $0,42^{* * *}$ & $0,43^{* * *}$ & $0,43^{* * *}$ & $0,41^{* * *}$ & $0,44^{* * *}$ \\
& $(0,026)$ & $(0,025)$ & $(0,025)$ & $(0,025)$ & $(0,024)$ \\
SGP & $0,79^{* * *}$ & $0,80^{* * *}$ & $0,79^{* * *}$ & $0,65^{* * *}$ & $0,69^{* * *}$ \\
& $(0,035)$ & $(0,034)$ & $(0,034)$ & $(0,035)$ & $(0,032)$ \\
SGR & $0,93^{* * *}$ & $0,95^{* * *}$ & $0,95^{* * *}$ & $0,76^{* * *}$ & $0,82^{* * *}$ \\
& $(0,045)$ & $(0,044)$ & $(0,044)$ & $(0,046)$ & $(0,042)$
\end{tabular}




\begin{tabular}{|c|c|c|c|c|c|}
\hline \multirow[b]{2}{*}{ Log(Predial) } & \multicolumn{5}{|c|}{ Panel con efectos fijos } \\
\hline & (1) & (2) & (3) & (4) & (5) \\
\hline \multirow{2}{*}{ DesarrolloRob*Transf } & & $0,24^{* * *}$ & $0,18^{* * *}$ & $0,19^{* * *}$ & $0,09 * * *$ \\
\hline & & $(0,036)$ & $(0,036)$ & $(0,035)$ & $(0,034)$ \\
\hline \multirow{2}{*}{ DesarrolloInt*Transf } & & $0,06^{* *}$ & 0,04 & $0,05^{*}$ & 0,03 \\
\hline & & $(0,024)$ & $(0,025)$ & $(0,027)$ & $(0,025)$ \\
\hline \multirow{2}{*}{ DesarrolloRob*Reg } & & & $0,04^{* * *}$ & $0,04^{* * *}$ & $0,04^{* * *}$ \\
\hline & & & $(0,011)$ & $(0,011)$ & $(0,010)$ \\
\hline \multirow{2}{*}{ DesarrolloInt*Reg } & & & $0,02^{* * *}$ & $0,02^{* * *}$ & $0,02^{* * *}$ \\
\hline & & & $(0,006)$ & $(0,006)$ & $(0,006)$ \\
\hline \multirow{2}{*}{$\log ($ Otros $)$} & & & & $0,06^{* * *}$ & $0,06^{* * *}$ \\
\hline & & & & $(0,006)$ & $(0,006)$ \\
\hline \multirow{2}{*}{ Log(Población) } & & & & & $0,76^{* * *}$ \\
\hline & & & & & $(0,068)$ \\
\hline \multirow{2}{*}{ Constante } & $2,36^{* * *}$ & $2,38^{* * *}$ & $2,38^{* * *}$ & $2,21^{* * *}$ & $-4,79 * * *$ \\
\hline & $(0,114)$ & $(0,113)$ & $(0,112)$ & $(0,121)$ & $(0,658)$ \\
\hline Observaciones & 28.852 & 28.852 & 28.852 & 27.977 & 27.972 \\
\hline Número de Municipios & 1.100 & 1.100 & 1.100 & 1.100 & 1.100 \\
\hline R-Cuadrado & 0,50 & 0,50 & 0,50 & 0,50 & 0,52 \\
\hline Rho & 0,86 & 0,81 & 0,82 & 0,81 & 0,77 \\
\hline
\end{tabular}

Nota: Rho representa la fracción de la varianza explicada por $u_{i} \cdot{ }^{*}, * *, * *$ indican niveles de significancia del $10 \%, 5 \%$ y $1 \%$, respectivamente. Errores estándar robustos en paréntesis. DesarrolloRob y DesarrolloInt hacen referencia a municipios con entornos de desarrollo robusto e intermedio, respectivamente.

Fuente: cálculos de los autores con datos del DNP. 
